\title{
Development and characterisation of acquired radioresistant breast cancer cell lines
}

Mark Gray ${ }^{1,2^{*}}$ D , Arran K. Turnbull ${ }^{2,3+}$, Carol Ward ${ }^{1,2}$, James Meehan ${ }^{2,4}$, Carlos Martínez-Pérez ${ }^{2,3}$, Maria Bonello ${ }^{2}$, Lisa Y. Pang ${ }^{1}$, Simon P. Langdon ${ }^{2}$, Ian H. Kunkler ${ }^{2}$, Alan Murray ${ }^{5}$ and David Argyle ${ }^{1}$

\begin{abstract}
Background: Radiotherapy plays an important role in the multimodal treatment of breast cancer. The response of a breast tumour to radiation depends not only on its innate radiosensitivity but also on tumour repopulation by cells that have developed radioresistance. Development of effective cancer treatments will require further molecular dissection of the processes that contribute to resistance.

Methods: Radioresistant cell lines were established by exposing MDA-MB-231, MCF-7 and ZR-751 parental cells to increasing weekly doses of radiation. The development of radioresistance was evaluated through proliferation and colony formation assays. Phenotypic characterisation included migration and invasion assays and immunohistochemistry. Transcriptomic data were also generated for preliminary hypothesis generation involving pathway-focused analyses.

Results: Proliferation and colony formation assays confirmed radioresistance. Radioresistant cells exhibited enhanced migration and invasion, with evidence of epithelial-to-mesenchymal-transition. Significantly, acquisition of radioresistance in MCF-7 and ZR-751 cell lines resulted in a loss of expression of both ERa and PgR and an increase in EGFR expression; based on transcriptomic data they changed subtype classification from their parental luminal $\mathrm{A}$ to HER2-overexpressing (MCF-7 RR) and normal-like (ZR-751 RR) subtypes, indicating the extent of phenotypic changes and cellular plasticity involved in this process. Radioresistant cell lines derived from ER+ cells also showed a shift from ER to EGFR signalling pathways with increased MAPK and PI3K activity.

Conclusions: This is the first study to date that extensively describes the development and characterisation of three novel radioresistant breast cancer cell lines through both genetic and phenotypic analysis. More changes were identified between parental cells and their radioresistant derivatives in the ER+ (MCF-7 and ZR-751) compared with the ER-cell line (MDA-MB-231) model; however, multiple and likely interrelated mechanisms were identified that may contribute to the development of acquired resistance to radiotherapy.
\end{abstract}

Keywords: Radioresistance, Breast cancer, Global gene analysis, ER and EGFR signalling, Characterisation of radioresistant cell lines

\footnotetext{
* Correspondence: s9900757@sms.ed.ac.uk

${ }^{\dagger}$ Mark Gray and Arran K. Turnbull contributed equally to this work.

${ }^{1}$ The Royal (Dick) School of Veterinary Studies and Roslin Institute, University

of Edinburgh, Edinburgh, Scotland

${ }^{2}$ Cancer Research UK Edinburgh Centre and Division of Pathology

Laboratories, Institute of Genetics and Molecular Medicine, Western General

Hospital, University of Edinburgh, Edinburgh, Scotland

Full list of author information is available at the end of the article
}

(c) The Author(s). 2019 Open Access This article is distributed under the terms of the Creative Commons Attribution 4.0 International License (http://creativecommons.org/licenses/by/4.0/), which permits unrestricted use, distribution, and reproduction in any medium, provided you give appropriate credit to the original author(s) and the source, provide a link to the Creative Commons license, and indicate if changes were made. The Creative Commons Public Domain Dedication waiver (http://creativecommons.org/publicdomain/zero/1.0/) applies to the data made available in this article, unless otherwise stated. 


\section{Background}

Radiotherapy (RT) is a commonly used adjuvant treatment modality for a variety of solid cancers. Up to $83 \%$ of breast cancer patients benefit from radiotherapy either with curative or palliative intent [1]. Multiple studies, including 6 randomized control trials and subsequent meta-analyses, have shown that breast conserving surgery (BCS) followed by whole breast RT achieves survival rates and long term local control equivalent to that seen with mastectomy, with the added advantages of relatively mild toxicity and good cosmetic outcome [2-4]. However, despite the successful use of adjuvant RT in breast cancer, some patients will still develop loco-regional recurrences following the completion of a RT course. While tumour recurrence following $\mathrm{RT}$ can be due to residual disease or aggressive tumour biology, it can also be due to the survival of a population of cells that either have a greater intrinsic resistance to RT (e.g. hypoxic or cancer stem cells) or develop de novo resistance. These radioresistant cells can then repopulate the tumour site leading to recurrence and treatment failure.

Improved understanding of the mechanisms underlying acquired radioresistance and the development of strategies to circumvent this clinical problem are required. Previous studies have shown that multiple factors are implicated in the development of radioresistance, including deregulated signalling pathways (e.g. PI3K/AKT, NF- B), oncogenic miRNA overproduction, enhanced DNA damage responses, the presence of cancer stem cells, epithelial-tomesenchymal transition (EMT) and alterations in cancer metabolism, along with the effect of the tumour microenvironment itself (including hypoxia) [5]. Many studies focus on isolated pathways when investigating radioresistance, but it is likely that these pathways are interrelated in complex networks; for example, hypoxia can cause a more undifferentiated cellular phenotype, characterised by an increased expression of stem cell markers, which can also affect the expression of genes and pathways controlling stemness, such as Oct4, Notch and EMT [6].

In comparison to the investigation of chemoresistance, the mechanisms underlying radioresistance development are poorly understood, partly due to a lack of radioresistant model systems. The use of global approaches to investigate resistance mechanisms is gaining interest, as this allows for the study of multiple pathways simultaneously and provides an overview of complex biological systems and response to treatment [7]. In this study we developed novel in vitro radioresistant cell lines from ER positive (ER+) and ER negative (ER-) breast cancer cell lines. Parental cell lines were chosen to represent different molecular subtypes of breast cancer and included MCF-7 and ZR-751 cell lines (ER+, PgR+, HER2-), which are hormone-dependent, and the MDA-MB-231 cell line, which is triple negative (ER-, PgR-, HER2-) and consequently hormone-independent. We undertook genotypic, phenotypic and functional characterisation of our radioresistant models, enabling us to corroborate our findings at the gene, protein and functional levels. This approach allowed us not only to identify differences between parental cells and their derived RR cell lines but also between ER+ and ER- cell lines. To our knowledge, our study is the first to develop a ZR-751 RR cell line and use multicellular tumour spheroids derived from RR cells in functional assays and immunohistochemical analysis.

\section{Methods \\ Cell culture}

Cell culture reagents were obtained from Gibco Thermo Fisher Scientific (Paisley, UK), unless otherwise stated. Human breast cancer cell lines ZR-751, MCF-7 and MDA-MB-231 were cultured in Dulbecco's modified Eagle's medium (DMEM) supplemented with $10 \%$ foetal calf serum (FCS), $50 \mathrm{U} \mathrm{ml}^{-1}$ penicillin and $50 \mathrm{mg} \mathrm{ml}^{-1}$ streptomycin and incubated at $37^{\circ} \mathrm{C}$ in a humidified atmosphere with $5 \% \mathrm{CO}_{2}$. Cell lines obtained from the American Type Culture Collection (LGC Standards, Teddington, UK) were authenticated by short tandem repeat (STR) profiling performed at Health England (Porton Down, Salisbury, UK). All cell line DNA samples tested matched 9 of 9 tested core alleles in DNA from known cell line samples confirming their identity. All experiments were performed using cells, maintained at low passage number from these frozen stocks.

\section{Irradiation of cells and development of radioresistant cell lines}

Cells were irradiated using a Faxitron cabinet X-ray system 43855D (Faxitron X-ray Corporation, IL, USA). Radioresistant cell lines (MCF-7 RR, ZR-751 RR and MDA-MB-231 RR) were developed from their respective parental cell lines (MCF-7, ZR-751 and MDA-MB-231) by weekly exposure to single fractions of radiation. An initial dose of 2 Gy was followed by weekly incremental doses of 0.5 Gy for 12 weeks. During this period cells received a total radiation dose of $57 \mathrm{~Gy}$. Cells were subsequently maintained with further weekly doses of $5 \mathrm{~Gy}$.

\section{Sulforhodamine B proliferation (SRB) assay}

Cells were seeded into 96 well plates (500 cells/well) and incubated for $24 \mathrm{~h}$. Cells were drug-treated or exposed to radiation and fixed between 24 and $144 \mathrm{~h}$ after treatment by the addition of $50 \mu$ l cold $25 \%$ trichloracetic acid (Sigma-Aldrich, UK) per well at $4{ }^{\circ} \mathrm{C}$ for $1 \mathrm{~h}$. Plates were washed in $\mathrm{H}_{2} \mathrm{O}$ and, when dry, $50 \mu \mathrm{l} \mathrm{SRB}$ dye (0.4\% SRB dissolved in $1 \%$ glacial acetic acid (VWR International)) was added to each well and incubated for $30 \mathrm{~min}$. Plates were washed 4 times in $1 \%$ glacial acetic acid and, when dry, $150 \mu \mathrm{l}$ of $10 \mathrm{mM}$ Tris- $\mathrm{NaOH}$ 
buffer ( $\mathrm{pH}$ 10.5) was added to each well. The plates were incubated on a shaker for $60 \mathrm{~min}$. Optical density was measured at $540 \mathrm{~nm}$ using a Biohit BP800 spectrophotometer (Biohit Ltd., UK) and Wallac 1420 Manager program (PerkinElmer, UK). The half maximal inhibitory concentrations $\left(\mathrm{IC}_{50}\right.$ values) were calculated using the GraphPad prism 7 package.

\section{Colony formation (CF) assay}

Cells were seeded into $75 \mathrm{~mm}$ plates $\left(1 \times 10^{3}\right.$ cells/plate $)$ and incubated for $24 \mathrm{~h}$ before radiation treatment. Once visible colonies had formed (approximately 50 cells per colony) in the untreated control group (approximately 10-14 days post-seeding) the plates were washed twice in PBS before fixing the cells with the addition of $5 \mathrm{ml}$ of 1,9-dimethyl-methylene blue zinc chloride double salt (Sigma-Aldrich, UK). After $45 \mathrm{~min}$ the plates were washed and allowed to air dry before colonies were counted. Analysis was performed by calculating plating efficiencies and survival fractions for control and treatment plates [8].

\section{Scratch (migratory) assays}

Cells were seeded into 6 well plates at a density to achieve $100 \%$ confluence after $24 \mathrm{~h}$. Scratch assays were performed as previously described [9]. $0.1 \%$ serum-supplemented media was added to each well. Phase contrast images of the cell monolayer were captured (Axiovert DS100, $\times 5$ objective) during migration up to a maximum of $48 \mathrm{~h}$ post-scratch. At each time point the area devoid of migrating cells was calculated using FIJI software and expressed as a $\%$ of the initial scratched area.

\section{Formation of multicellular tumour spheroids (MTS)}

A single cell suspension of each cell line from a T175 flask (approximately $15 \times 10^{6}$ cells) was transferred to a spinner flask (Cellcontrol Spinner Flask, Integra, Switzerland) containing $100 \mathrm{ml}$ of routine DMEM and placed onto a magnetic stirrer platform (Cellspin, Integra, Switzerland). MTS developed over 7 days in normal incubation conditions.

\section{D invasion assay using multicellular tumour spheroids}

A single MTS was removed with $500 \mu \mathrm{l}$ of collagen mix (ice cold $0.1 \%$ filtered acetic acid, cell matrix type 1-A (Alphalabs), $0.22 \mathrm{M} \mathrm{NaOH}$ (Sigma-Aldrich, UK), FCS and 10x DMEM (Sigma-Aldrich, UK) at concentrations of 45, 25, 10,10 and $10 \%$, respectively) and placed into a 24 well plate. Cultures were incubated for $1 \mathrm{~h}$ to allow polymerisation of collagen and $500 \mu \mathrm{l}$ routine DMEM was then added to each well. Phase contrast images were captured (Axiovert DS100, $\times 5$ objective) at regular intervals up to $120 \mathrm{~h}$ post-seeding. MTS invasion was measured using a FIJI macro developed by Matthew Pearson (IGMM Advanced Imaging Resource, University of Edinburgh) at each time point and expressed as a \% of the initial MTS area.

\section{Assessment of the effects of radiation on pathway activation}

Cells were seeded into $75 \mathrm{~mm}$ plates $\left(1.0 \times 10^{6}\right.$ cells/plate $)$ and incubated for $24 \mathrm{~h}$. Cells were serum-starved for $2 \mathrm{~h}$ and exposed to $2 \mathrm{~Gy}$ radiation before undergoing routine lysis collection at $0,5,10$ and $30 \mathrm{~min}$ post-radiation. Lysates were snap frozen on dry ice and stored at $-70^{\circ} \mathrm{C}$ for western blot analysis.

\section{Protein isolation and detection}

Whole cell lysates were prepared as previously described [10] and protein concentration was determined using a bicinchoninic acid (BCA) assay. Equal amounts of protein were separated by sodium dodecyl sulphate (SDS) polyacrylamide gel electrophoresis and transferred to Immobilon-P transfer membrane (Millipore). Ponceau S solution was used to visualise protein bands and confirm equal loading; membranes were blocked using Odyssey Blocking Buffer (LI-COR Biosciences, UK) (1:1 with PBS) for $1 \mathrm{~h}$, before incubating overnight at $4{ }^{\circ} \mathrm{C}$ with primary antibodies (Table 1). Signals were detected using IRDye 800CW (Li-Cor, 926-32,210, 1:10,000) and IRDye 680LT (Li-Cor 926-68,021, 1:10,000) with a Li-Cor Odyssey Imager. Membranes required for re-probing were stripped using NewBlot PVDF Stripping Buffer (LI-COR Biosciences, UK).

\section{Immunohistochemistry (IHC) and immunocytochemistry} (ICC)

IHC was carried out on formalin-fixed MTS. Samples were deparaffinised and rehydrated, and antigens retrieved (Table 1). Endogenous peroxidase activity was inhibited with $3 \% \mathrm{H}_{2} \mathrm{O}_{2}$ solution (Dako, UK) for $10 \mathrm{~min}$ and non-specific antibody staining was blocked using Total Protein Block (Dako, UK) for $10 \mathrm{~min}$. Primary antibodies were incubated for $1 \mathrm{~h}$ (Table 1). 1 drop of Envision labelled polymer (Dako, UK) was added for 30 min, before DAB and substrate buffer (1:50) (Dako, UK) were added to each section for $10 \mathrm{~min}$.

ICC was performed on cells grown in chamber slides (2 well chamber slide, Lab-Tek II, Scientific Laboratory Supplies, UK) seeded to achieve a confluency of approximately $80 \%$ at $24 \mathrm{~h}$. Cells were fixed in cold acetone (500 $\mu \mathrm{l} /$ chamber) for $10 \mathrm{~min}$ at $4{ }^{\circ} \mathrm{C}$, then washed twice in PBS for $10 \mathrm{~min}$. The same protocol as described for MTS IHC, from the addition of $\mathrm{H}_{2} \mathrm{O}_{2}$ solution, was then followed.

All slides were counterstained in haematoxylin, dehydrated and mounted with coverslips using DXP mountant (Sigma-Aldrich, UK). Slides were scanned using a NanoZoomer ER slide scanner (Hamamatsu Photonics, UK) and viewed using NanoZoomer Digital Pathology software. 
Table 1 Primary antibodies used for western blotting (WB), immunocytochemistry (ICC) and immunohistochemistry (IHC)

\begin{tabular}{llll}
\hline Primary antibody target antigen & Antibody Details & Dilutions and applications & Antigen retrieval \\
\hline Anti-a tubulin & Mouse MAb; Abcam; ab7291 & $1: 10,000$ (WB) & N/A \\
Anti-ERa & Mouse MAb; Dako; M7047 & $1: 50$ (WB, ICC, IHC) & Sodium citrate \\
Anti-EGFR & Rabbit MAb; Cell Signalling Technology; 4267 & $1: 1000$ (WB); 1:50 (ICC, IHC) & EDTA \\
Anti-HER2 & Rabbit MAb; Cell signalling Technology; 2242 & $1: 1000$ (WB); 1:50 (ICC, IHC) & Sodium citrate \\
Anti-PgR (A/B) & Rabbit MAb; Cell Signalling Technology; 8757 & $1: 1000$ (WB) & N/A \\
Anti-PgR & Mouse Mab; DAKO; M3569 & $1: 150$ (ICC, IHC) & EDTA \\
Anti-AKT & Mouse MAb; Cell Signalling technology; 2920 & $1: 1000$ (WB) & N/A \\
Anti-Phospho AKT & Rabbit PAb; Cell Signalling technology; 9271 & $1: 1000$ (WB) & N/A \\
Anti-ERK & Rabbit PAb; Cell Signalling Technology; 9102 & $1: 1000$ (WB) & N/A \\
Anti-Phospho ERK & Mouse MAb; Cell Signalling Technology; 9106 & $1: 1000$ (WB) & N/A \\
Anti-ki67 & Mouse MAb; DAKO; M7240 & $1: 150$ (ICC, IHC) & Sodium citrate \\
Anti-E-cadherin & Mouse MAb; BD Transduction; 610,182 & $1: 50$ (ICC, IHC) & Sodium citrate \\
Anti-N-cadherin & Mouse MAb; BD Transduction; 610,921 & $1: 150$ (ICC, IHC) & Sodium citrate \\
Anti-vimentin & Mouse Mab; Abcam; 8069 & $1: 50$ (ICC, IHC) & Sodium citrate \\
Anti-SNAlL & Rabbit PAb; Abcam; 128,530 & $1: 250$ (ICC, IHC) & Sodium citrate \\
\hline
\end{tabular}

\section{siRNA transfection}

Cells were seeded into 96 or 6 well plates (500 or $2 \times 10^{5}$ cells per well, respectively) in media without antibiotics and incubated overnight to achieve $30-50 \%$ confluence. Cells were transfected according to the manufacturer's protocol using DharmaFECT 1 Transfection Reagent (Dharmacon) with on-target plus ER $\alpha$ siRNA (J-103401-12) (GE Healthcare Dharmacon) at a concentration of $25 \mathrm{nM}$.

\section{RNA extraction and whole-transcriptome gene expression analysis}

Cells were seeded into $75 \mathrm{~mm}$ plates $\left(3.0 \times 10^{6}\right.$ cells/ plate) and incubated for $24 \mathrm{~h}$. Cells were serum-starved for $2 \mathrm{~h}$ and were then exposed to either 0 or $2 \mathrm{~Gy}$ radiation. Pellets of up to $1 \times 10^{7}$ cells were collected by trypsinisation at 0,2 and $8 \mathrm{~h}$ post-radiation, snap-frozen on dry ice and stored at $-70{ }^{\circ} \mathrm{C}$ for subsequent RNA extraction. Total RNA was extracted from cells with the RNeasy Mini Kit using QIAshredder technology (UK Qiagen, Ltd). The manufacturer's protocol for purification of total RNA from animal cells using spin technology was followed. Extracted RNA samples were quantified and assessed for the presence of contaminants using the NanoDropTM Spectrophotometer ND1000 (Thermo Fischer Scientific). Full genome expression read-counts were generated using Lexogen QuantSeq 3' FWD sequencing technology on an Illumina flow cell which was scanned using an Illumina HiScanSQ system (Edinburgh Clinical Research Facility, University of Edinburgh). NGS reads were generated towards the poly(A) tail and read 1 directly reflects the mRNA sequence. The ZR-751 2 h, 2 Gy sample failed sequencing and was removed from further analysis. RNA integrity number (RIN) was generated for each sample to assess RNA quality (Agilent Bioanalyzer); all samples had RIN values above 9.7 (Additional file 1: Table S1). FASTQ files of raw read-count data were pre-processed using the Lexogen recommended BlueBee high-performance NGS analysis software which implemented poly(A) tail trimming and alignment to the Genome Reference Consortium Human genome build 38 reference genome using the Spliced Transcripts Alignment to a Reference (STAR) algorithm [11]. Prior to analysis, data were $\log 2$ transformed and quantile normalised in $\mathrm{R}$ (Bioconductor) software and packages [12]. These preliminary transcriptomic data were only used for supervised pathway-focused analyses for the purposes of hypothesis generation and each analysis was subsequently validated by lab-based experimentation. Heatmap and cluster analysis were performed using TM4 MeV (multiple experiment viewer) software [13]. Heatmap clustering was carried out using Pearson correlation with average linkage. For integration of gene expression data with public datasets correction for integration batch effects was performed in $\mathrm{R}$ using ComBat as described previously [14, 15]. Hierarchical clustering of parental and RR cell lines was performed using a published list of genes whose expression profile denotes the breast cancer intrinsic subtypes (basal, normal-like, Her2, luminal A and luminal B) [16]. Assignment of individual samples to intrinsic subtypes was performed using the genefu R package [17]. Genefu implements a Single Sample Predictor (SSP) algorithm which is a nearest-centroid classifier. The centroids representing the breast cancer molecular subtypes were identified through hierarchical clustering using the same intrinsic gene list that we used for cluster analysis in this 
study. All datasets generated and/or analysed during the current study are available in the NCBI's Gene Expression Omnibus [18] and are accessible through GEO Series accession number GSE120798.

\section{Immunohistochemistry and statistical analysis}

Image analysis software QuPath version 0.1.2 [19] was used to analyse ki67 and ER $\alpha$ target protein expression. Two-way ANOVA with Holm-Sidak's multiple comparisons test was used to test for differences between 2 groups in CF, SRB, invasion and migration assays and western blot experiments. Unpaired (two tailed) $t$-test was used to assess differences between 2 groups in IHC analysis. $P$ values $<0.05$ were deemed statistically significant. Data is shown as mean \pm SEM with all statistical analysis and graphs generated with GraphPad Prism 7. An overview of the samples included in each experiment (including cell line, time points, treatments and number of replicates) is provided in Additional file 2: Table S2.

\section{Results}

Development and confirmation of the acquisition of radioresistance in ER+ and ER- breast cancer cell lines Radioresistant cell lines (MCF-7 RR, ZR-751 RR and MDA-MB-231 RR) were developed from their parental cell lines (MCF-7, ZR-751 and MDA-MB-231) by weekly exposure to single fractions of radiation, increasing by 0.5 Gy per week over a period of 12 weeks; cells were subsequently maintained by weekly doses of $5 \mathrm{~Gy}$. Although maintenance radiation doses were still accompanied by cell death in all 3 RR cell lines, this was significantly less than that seen during the initial 12 week development period. Radioresistance was confirmed by both CF and SRB assays. The CF ability of all RR cell lines was significantly higher than their respective parental cell lines when exposed to a single dose of radiation up to 6 Gy (Fig. 1a). Significantly less inhibition of proliferation was also seen in the RR cell lines compared to their parental cell lines when exposed to a single dose of radiation up to $10 \mathrm{~Gy}$ (Fig. 1b). The $\mathrm{IC}_{50}$ (the dose of radiation required to reduce cell number by $50 \%$ ) values were higher in the RR cell lines when compared to their parental cells (Table 2). MCF-7 RR and MCF-7 RR cells which had not received radiation for 6 months (MCF-7 rr) were similarly radioresistant (Additional file 3: Figure S1), suggesting the longevity of the changes involved in the acquisition of this phenotype.

\section{Radioresistant cell lines have concurrent lower expression of cell cycle associated genes and modified basal proliferation rates relative to their parental cells}

SRB assays were used initially to assess proliferation rates in 2D cultures (Fig. 2a). Results showed lower rates

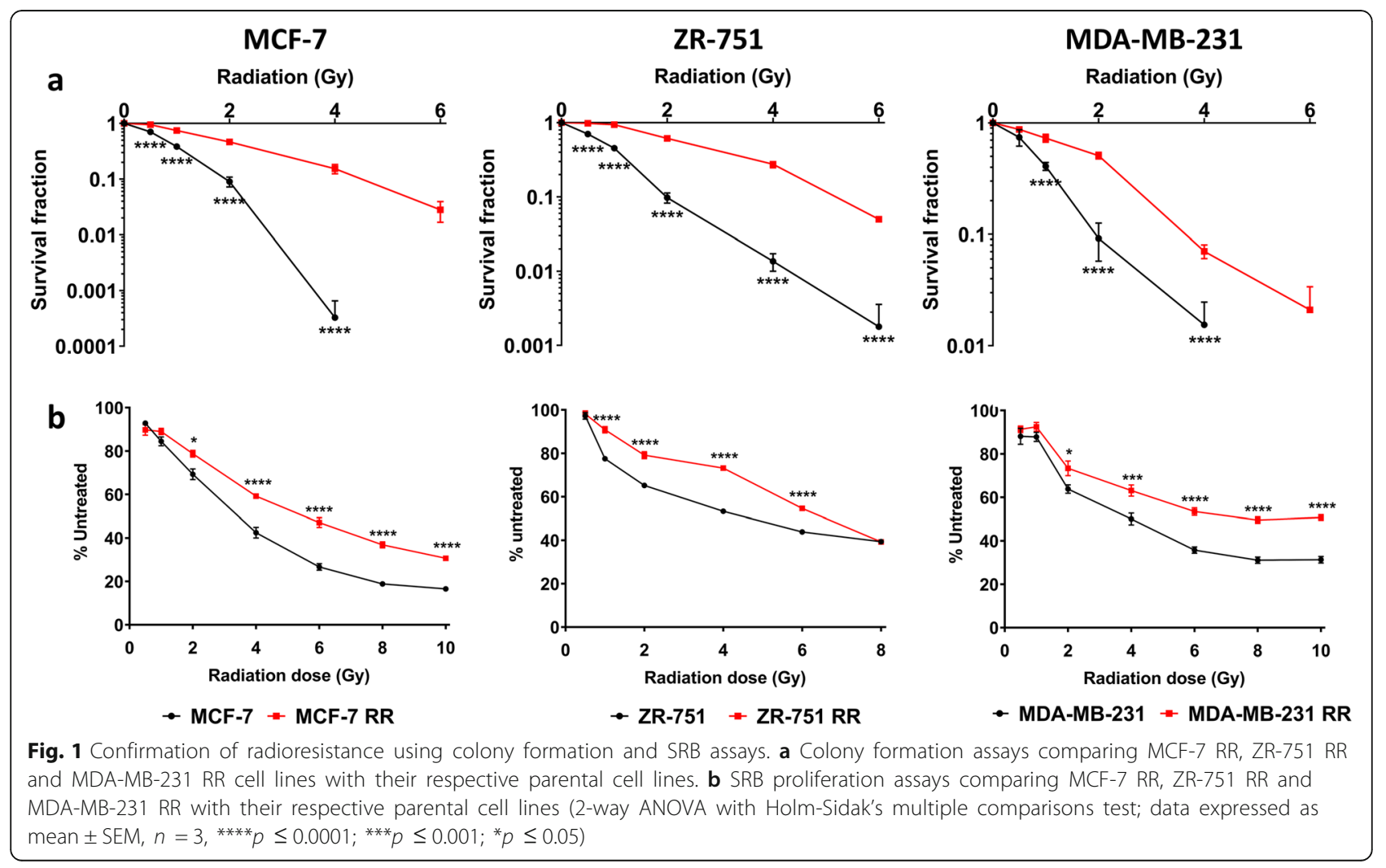


Table 2 Table of $\mathrm{IC}_{50}$ values for each parental and RR cell line up to $144 \mathrm{~h}$ post-exposure to radiation. If no value is recorded this indicates that a reduction in proliferation by $50 \%$ at that time point had not occurred; MCF-7 and MDA-MB-231 cell lines were evaluated up to $120 \mathrm{~h}$ post radiation whereas ZR-751 cell line was evaluated up to $144 \mathrm{~h}$ post radiation

\begin{tabular}{lllllll}
\hline Time Post Radiation $(\mathrm{h})$ & MCF-7 & MCF-7 RR & ZR-75-1 & ZR-75-1 RR & MDA-MB-231 & MDA-MB-231 RR \\
\hline 24 & - & - & - & - & - & - \\
48 & - & - & - & - & - & - \\
72 & 4.98 & 9.64 & - & - & 3.53 & 9.71 \\
96 & 3.27 & 5.36 & - & - & 3.13 & 7.11 \\
120 & 3.74 & 5.22 & - & N/A & N/A \\
144 & N/A & N/A & 4.38 & 6.91 & & \\
\hline
\end{tabular}

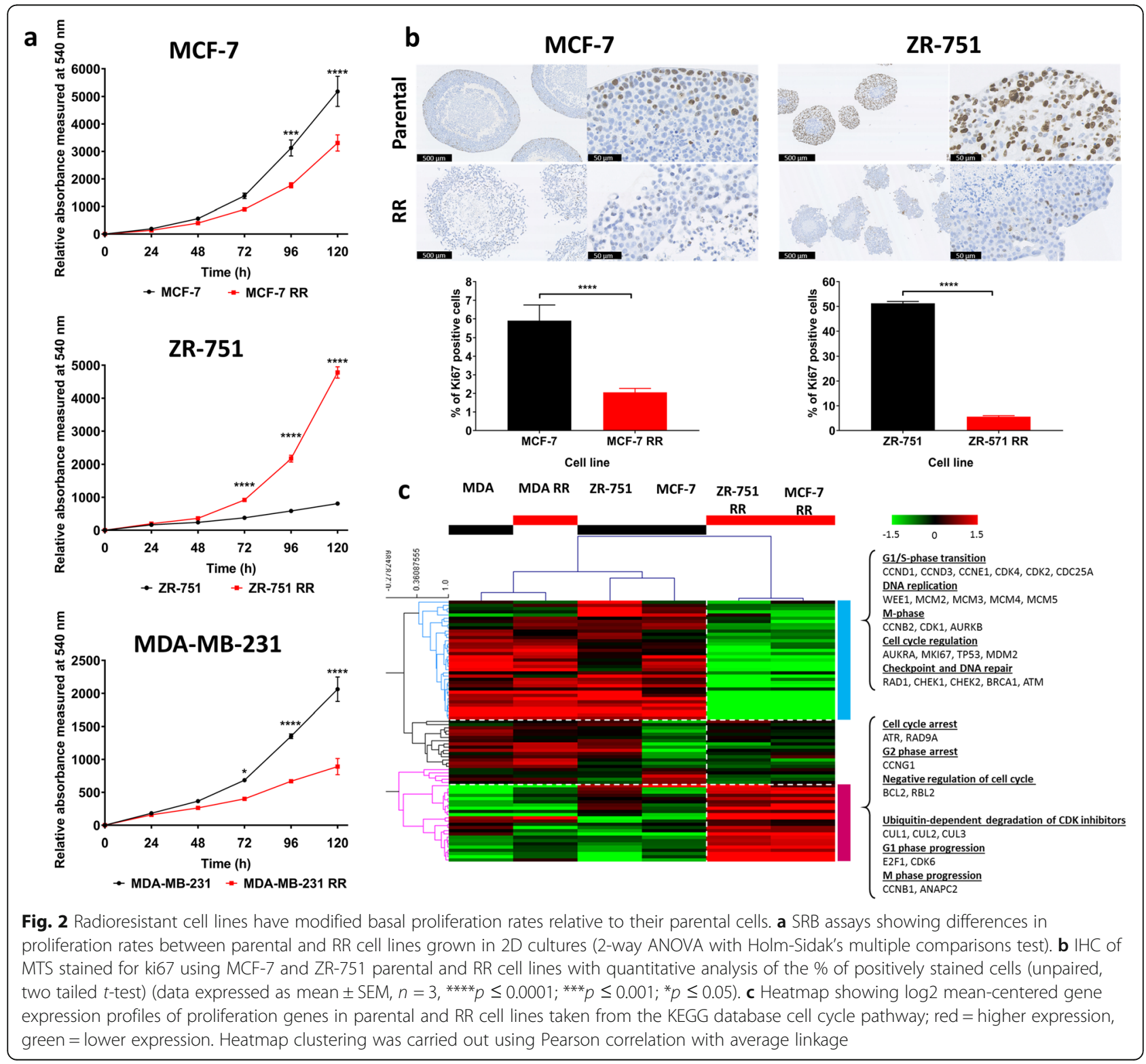


of proliferation in the MCF-7 RR and MDA-MB-231 RR and higher rates in the ZR-751 RR cell lines in comparison to their respective parental cell lines. Further investigation of proliferation was performed through $3 \mathrm{D}$ assays using IHC staining for the proliferation marker Ki67 in MCF-7 and ZR-751 parental and RR MTS (Fig. 2b) (MDA-MB-231 cell lines failed to develop MTS which could withstand IHC processing). IHC with quantitative analysis showed a lower percentage of positively stained ki67 cells in the RR MTS suggesting lower basal proliferation rates than their parental cell lines. Using gene expression data from 2D cultures, MCF-7 RR and ZR-751 RR cell lines were characterised by lower expression of genes involved in DNA replication and repair and those related to G1/S-phase transition and regulation of cell cycle, including AURKA and TP53, along with the higher expression of cell cycle arrest genes. Fewer changes in these genes were identified in the triple negative MDA-MB-231 parental and RR cell lines, both of which clustered next to each other and the MCF-7 and ZR-751 parental cell lines (Fig. 2c).

\section{Radioresistant cell lines have increased invasion and migration potential}

Epithelial-to-mesenchymal transition (EMT) is considered a normal feature of embryogenesis involved with cellular movement and morphogenesis during embryonic development [20] and may be an inherent property of normal basal stem cells in the breast [21]. However, the process can also be involved in tumour development with the conversion of early stage non-invasive tumours into invasive malignancies [22]. Acquisition of an EMT phenotype is associated with increased migration and invasion potential. Here, using a 3D invasion assay, we showed that both MCF-7 RR and ZR-751 RR have increased invasive potential compared to parental cells (which demonstrated little or no invasive capabilities); although the MDA-MB-231 RR cell line showed a slight increase in invasiveness at $72 \mathrm{~h}$, this was not statistically significant (Fig. 3a). Similarly, we assayed for migration potential using a $2 \mathrm{D}$ scratch assay and showed that all 3 RR cell lines had significantly enhanced migratory ability compared to their parental cells (Fig. 3b).

Parental ER+ cell lines exhibited a typical epithelial-like morphology, consisting of tightly packed cells forming cobblestone-like monolayers, with the cells consisting of a large nucleus and small amount of cytoplasm. By 12 weeks post-radiation, morphological changes were observed in their RR derivatives (Fig. 4a). Individual cells or those growing in small clusters gained a more spindle-shaped morphology with a larger amount of cytoplasm, with the contact between cells now via focal points rather than cell clusters. The MDA-MB-231 cell line already exhibited a mesenchymal-like phenotype, and phenotypic changes in its RR derivate were not obvious.
The observed change in cell morphology with the acquisition of radioresistance is consistent with cells undergoing EMT. We therefore investigated the expression levels of EMT markers using IHC for the MCF-7 and ZR-751 parental and RR cell lines and identified increased expression of vimentin, N-cadherin and SNAIL, along with the partial down regulation of E-cadherin in the RR cell lines. The MDA-MB-231 cell line was characterised by high vimentin along with low N-cadherin and E-cadherin expression; no differences between parental and its RR derivative were identified (Fig. $4 \mathrm{~b}$ and Additional file 4: Figure S2 and Additional file 5: Figure S3). These results were recapitulated using gene expression analysis from a published EMT signature (Fig. 4c) [23]. This study combined bioinformatic expression data analysis from both The Cancer Genome Atlas and Cancer Cell Line Encyclopaedia databases of seven tumour types which identified a pan-cancer EMT-associated gene expression signature. The lists of genes used have been provided in Additional file 6: Table S3. In our analysis, the MCF-7 and ZR-751 parental cell lines had a pattern of expression consistent with an epithelial genotype, whereas the MDA-MB-231 (both parental and RR) cells had higher expression of the mesenchymal cluster of genes. The MCF-7 RR and ZR-751 RR cell lines had a mixed pattern of expression with relatively high expression of both epithelial and mesenchymal genes, suggesting a transition from an epithelial towards a mesenchymal expression profile (Fig. 4c).

\section{WNT signalling is increased in ER+ derived radioresistant cell lines}

Analysis of transcriptomic data from ER+ parental and RR cell lines in respect of the WNT signalling pathway was investigated due to its reputed role in EMT and radioresistance [24]. The WNT pathway was investigated using panels of WNT signalling pathway members and down-stream targets, taken from the KEGG database [25]. The lists of genes used have been given in Additional file 6: Table S3. In this analysis the MCF7 RR and ZR-751 RR cell lines had a pattern of expression consistent with WNT pathway activation enriched for genes including FRIZZLED family members $1 / 2 / 5 / 7$, WNT5a and WNT5b (Fig. 5a). IHC using MCF-7 and ZR-751 parental and RR MTS showed increased expression of WNT5a in the radioresistant cell lines which was predominantly expressed in the cells located in the outer proliferating layer of the MTS (Fig. 5b). Further validation through western blot analysis of serum starved whole cell lysates (in accordance with gene analysis experiments) also showed increased WNT5a expression in the radioresistant cell lines at 0 and $24 \mathrm{~h}$ post-serum starvation (Fig. 5c). 


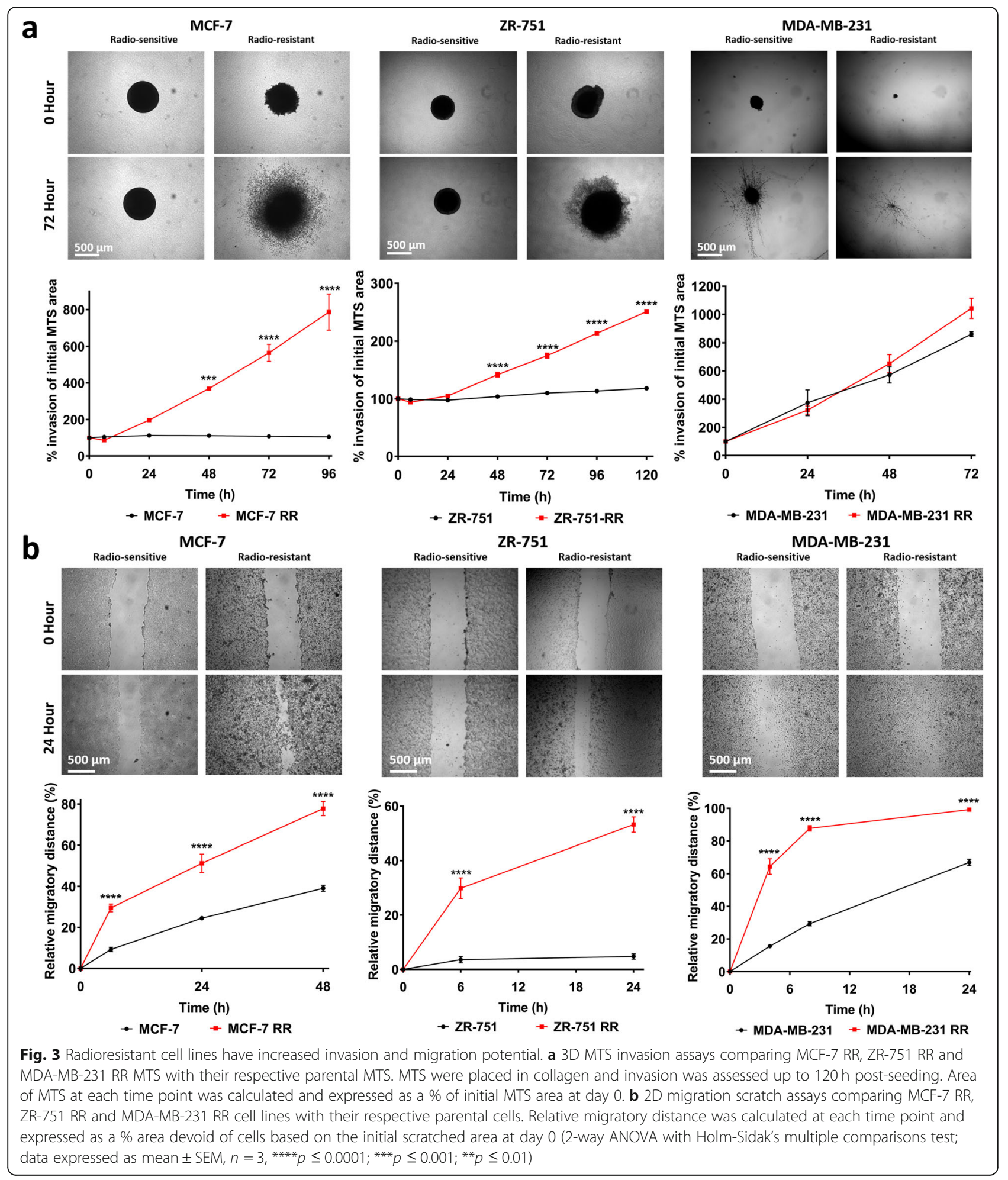

Radioresistant MCF-7 and ZR-751 cell lines show loss of $\mathrm{ERa}$ and $\mathrm{PgR}$ expression and gain in EGFR expression Breast cancer subtypes can be characterised by the expression profiles of key signalling receptors (ER $\alpha, \operatorname{PgR}$, HER2 and EGFR). Western blotting and IHC showed that the RR phenotype in the cell lines derived from ER+ cells was characterised by the loss of ER $\alpha$ and PgR expression, along with a gain in total EGFR expression (Fig. 6A \& B and Additional file 7: Figure S4 and Additional file 8: Figure S5). ICC with quantitative analysis 


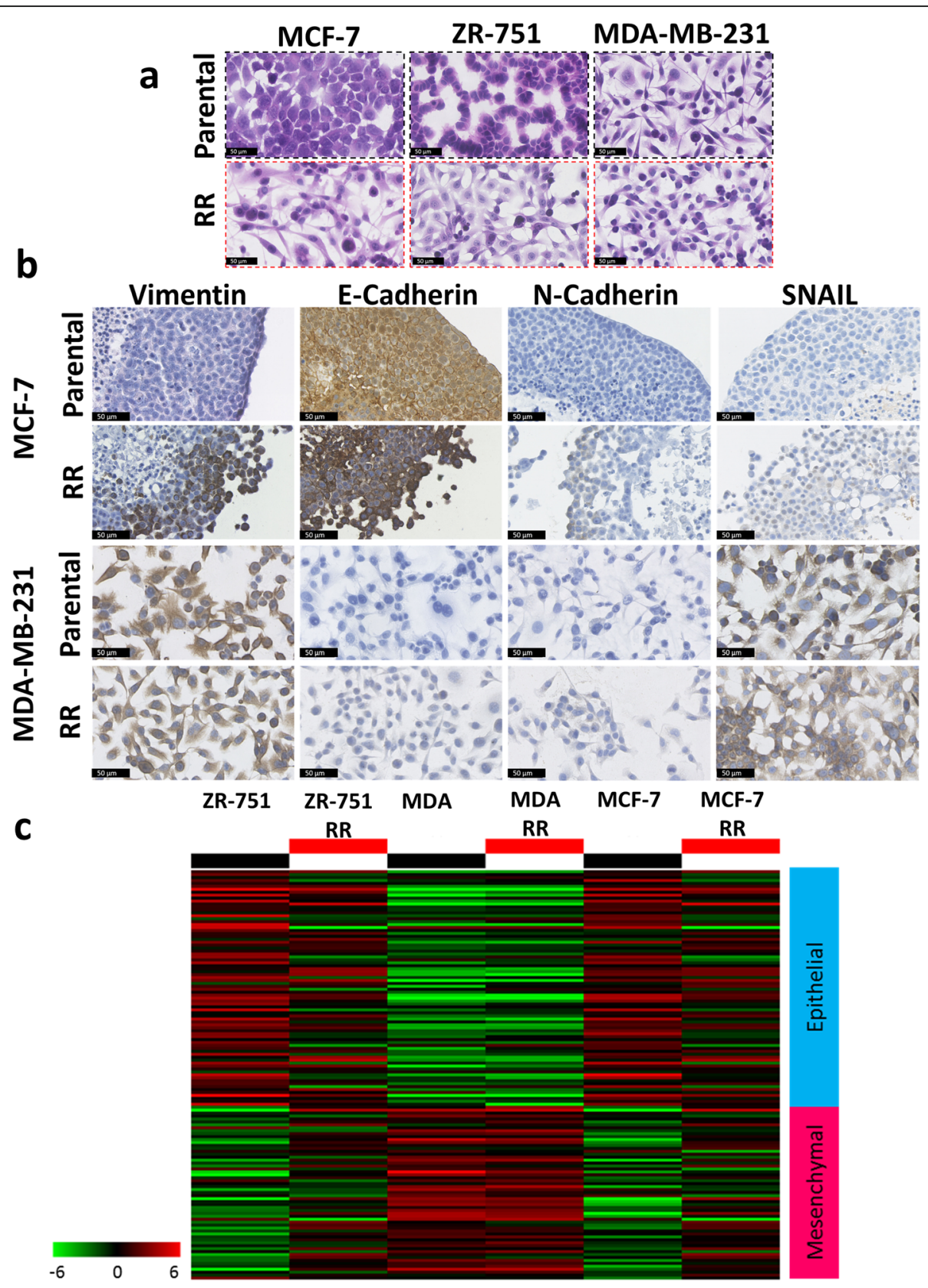

Fig. 4 MCF-7 RR and ZR-751 RR cell lines show increased expression of vimentin, N-cadherin and SNAIL with the partial down regulation of Ecadherin. a H\&E staining of parental and RR cell lines detailing their morphological differences. $\mathbf{b} \| \mathrm{HC}$ staining of EMT markers (vimentin, N-cadherin, SNAIL and E-cadherin) in MCF-7 and MDA-MB-231 parental and RR MTS and cells. c Heatmap showing log2 mean-centered gene expression profiles in respect of a published cancer cell EMT-signature [23]; red = higher expression, green = lower. The gene list and the order in which they appear in the heatmap are shown in Additional file 6: Table S3

confirmed reduction in the percentage of cells staining positive for ER $\alpha$ expression in the MCF-7 RR $(0.27 \pm 0.17 \%)$ cell line compared with the parental MCF-7 cell line $(81 \pm 1.1 \%)$ and in the ZR-751 RR $(0.52 \pm 0.36 \%)$ cell line compared with the parental ZR-751 (96.5 $\pm 1.8 \%)$ cell line. No Staining was seen in the MDA-MB-231 cell line or its RR derivative.
Three replicates with a minimum of 10 spheroids were included in each analysis. To investigate the consequences of this gain in EGFR expression, we treated parental and RR cells with increasing doses of the EGFR inhibitor, gefitinib, and determined its effect on the proliferation and migration of ER+ parental and RR cell lines. There was a statistically significant 


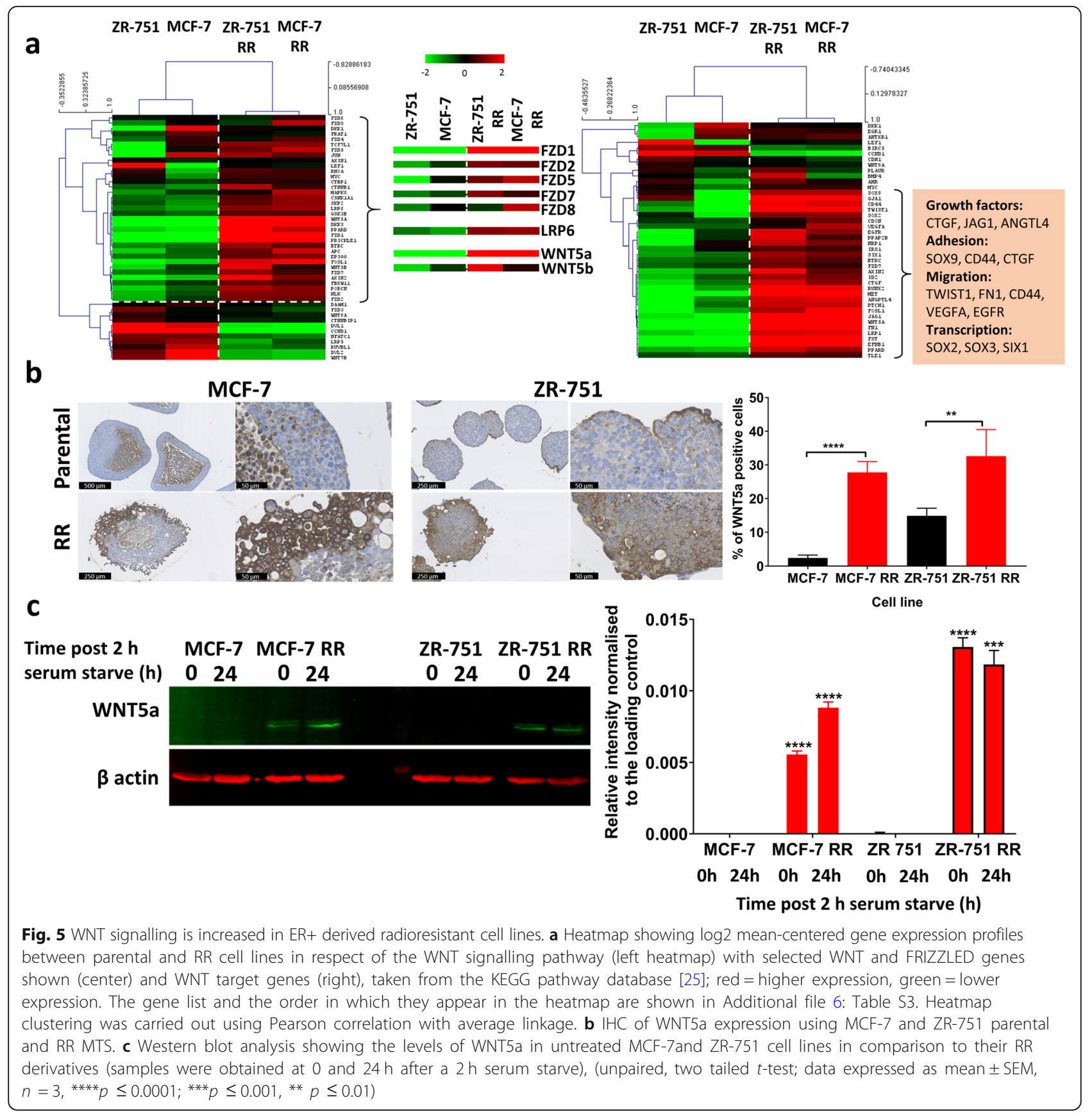

decrease in MCF-7 RR proliferation after $72 \mathrm{~h}$ with gefitinib concentrations ranging from $0.1-15 \mu \mathrm{M}$ compared to the parental cell lines ( $\mathrm{IC}_{50}$ : MCF-7 $13.36 \mu \mathrm{M}, \mathrm{MCF}-7 \mathrm{RR} 6.43 \mu \mathrm{M})$ and a significant reduction in migration, with a dose of $5 \mu \mathrm{M}$ decreasing the migratory potential of the RR cell line to parental levels (Fig. 6Ci \& Cii). Similar results were also seen in the ZR-751 parental and RR cell lines when treated with gefitinib (Additional file 9: Figure S6). As we had identified a loss in ER $\alpha$ expression, we also examined the effects of tamoxifen on the cell lines.
After $72 \mathrm{~h}$ of tamoxifen treatment there was a statistically significant increase in proliferation of the MCF-7 RR cell line compared to the parental cell line at concentrations ranging from $0.01-3 \mu \mathrm{M}$ (Fig. 6Ciii).

ERa knockdown in MCF-7 cells results in EGFR expression, reduction in proliferation and enhancement of radiosensitivity

The loss of ER $\alpha$ in the MCF-7 cell line was further investigated using ER $\alpha$ siRNA knockdown. ER $\alpha$ knockdown was associated with increased EGFR expression 96 and 120 


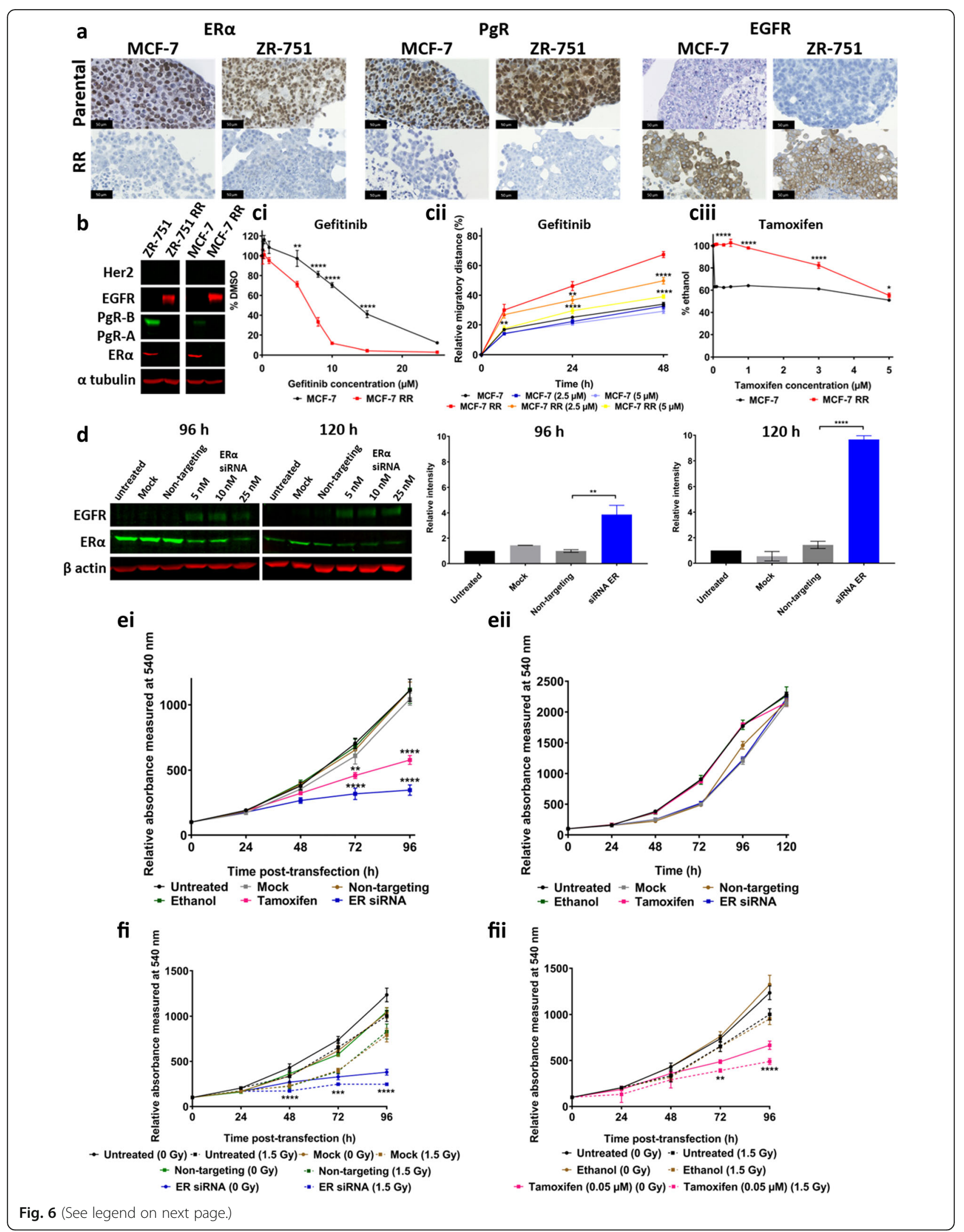


(See figure on previous page.)

Fig. 6 Radioresistant MCF-7 and ZR-751 cells show loss of ERa and PgR expression and gain in EGFR expression with a shift from ER to EGFR signalling pathways. $\mathbf{A}$ and $\mathbf{B}$ Expression profiles of signalling receptors, ERa, PgR, Her2 and EGFR in MCF-7 and MCF-7 RR cell lines using $\mathbf{A} \| H C$ with MTS and $\mathbf{B}$ Western blot analysis. Ci SRB at $72 \mathrm{~h}$ and Cii scratch assay at 24 and $48 \mathrm{~h}$ showing the effects of the gefitinib in MCF-7 and RR cell lines. Ciii SRB assay showing the effect of tamoxifen in MCF-7 and RR cell lines at $72 \mathrm{~h}$. D Levels of EGFR expression increased 96 and $120 \mathrm{~h}$ after ERa siRNA knockdown. Graphs document the relative intensity of EGFR normalised to the loading controls using $25 \mathrm{nM}$ of ERa siRNA. Ei\&ii SRB assay showing significant reduction in proliferation of the MCF-7 cells after $72 \mathrm{~h}$ treatment with either ERa siRNA ( $25 \mathrm{nM}$ ) or tamoxifen $(0.05 \mu \mathrm{M})$, whereas no reduction in proliferation was seen in MCF-7 RR cells. Fi\&ii SRB assay showing an additional reduction in MCF-7 proliferation following ERa knockdown or tamoxifen treatment when combined with radiation $24 \mathrm{~h}$ after transfection/tamoxifen treatment (2-way ANOVA with Holm-Sidak's multiple comparisons test; data expressed as mean \pm SEM, $n=3,{ }^{* * * *} p \leq 0.0001 ;{ }^{* *} p \leq 0.01 ;{ }^{*} p \leq 0.05$ )

$\mathrm{h}$ after transfection, as shown through western blot analysis (Fig. 6D). There was also a significant reduction in proliferation of the MCF-7 cells after $72 \mathrm{~h}$ treatment with either ER $\alpha$ siRNA $(25 \mathrm{nM})$ or tamoxifen $(0.05 \mu \mathrm{M})$ (Fig. 6Ei), whereas no reduction in proliferation was seen in the MCF-7 RR cells (6Eii). An additional reduction in MCF-7 proliferation was observed when ER $\alpha$ knockdown or tamoxifen treatment was combined with radiation $24 \mathrm{~h}$ after transfection/tamoxifen treatment (Fig. 6Fi\&ii), suggesting a radiosensitising rather than a radioprotective effect from ER $\alpha$ loss.

\section{Radioresistant cell lines exhibit cellular plasticity within the context of intrinsic breast cancer subtyping}

ER signalling was further investigated through the application of a published gene expression signature for ER pathway signalling activity to our transcriptomic data [26]. As expected, the ER+ parental cell lines (MCF-7 and ZR-751) were characterised by high expression of these genes whereas the ER- parental and RR cell lines (MDA-MB-231) had lower expression. Interestingly, the MCF-7 RR and ZR-751 RR cells clustered with the ERcell lines in hierarchical clustering analysis, although they maintained higher expression levels, similar to their parental cells, for a subset of these genes. Treatment with 2 Gy of radiation for 2 and $8 \mathrm{~h}$ was not found to influence the expression of these genes (Fig. 7a).

Gene expression data was integrated with a public gene expression dataset (GSE50811) of 67 breast cancer cell lines. The MDA-MB-231 parental and RR cell lines, both treated and untreated, clustered tightly with each other in the dendrogram branch enriched for the basal breast cancer subtype. Both treated and untreated MCF-7 and ZR-75-1 parental cell lines were classified as luminal A whereas their RR derivates clustered independently and were enriched for normal-like (ZR-751 RR) and HER2-overexpressing (MCF-7 RR) intrinsic subtypes (Fig. 7b and Additional file 10: Figure S7).

\section{PI3K and MAPK activity are increased in ER+ derived radioresistant cell lines}

Downstream signal transduction pathways of the HER/ ERBB tyrosine-kinase receptor family were further investigated following identification that total EGFR expression was increased in the ER+ derived RR cell lines. Western blot analysis of time course experiments up to 30 min after $2 \mathrm{~Gy}$ radiation showed increased levels of p-ERK in MCF-7 RR and ZR-751 RR cell lines 5 min post-radiation, whereas a smaller increase was seen in the parental cell lines at a later time point (Fig. 8a). Although p-AKT did not show increased levels in response to radiation, the RR cell lines had overall increased expression levels compared with the parental cell lines (Fig. 8b). No differences were seen in the MDA-MB-231 and RR cell lines. The activity of the MAPK pathway in our cell lines was investigated using a published gene expression signature [27]. PI3K activity was assessed using genes taken from the KEGG pathway database [25] in combination with FOXO-regulated genes (these have an inverse expression pattern to PI3K activity) [28]. Gene expression analysis suggested that active MAPK and inactive PI3K signalling were constitutive in the MDA-MB-231 parental and RR cell lines and expression levels of these signalling pathways were not affected by radiation treatment. The untreated ER+ cell lines were characterised by both inactive MAPK and PI3K activity, whereas their RR derivatives had lower overall expression of the MAPK-associated genes, potentially representing a switch to active MAPK and PI3K signalling (Fig. $8 \mathrm{c}$ and d).

\section{Discussion}

Intrinsic or acquired radioresistance can be a significant obstacle in the treatment of many cancers, including breast. In this study we developed novel radioresistant cell lines from both ER+ and ER- breast cancer cell lines and characterised their inherent differences and responses to radiation through genetic, molecular and cell biology approaches. Radioresistance was acquired in all 3 RR cell lines, which validated their use as an in vitro model system to help characterise this phenotype and investigate the mechanisms involved in radioresistance development and treatment failures in patients. The radioresistant phenotype was also shown to be maintained in MCF-7 RR cells that were not exposed to radiation for 6 months indicating that the acquisition of radioresistance is not transient. This has important therapeutic implications and is in contrast to a previous 


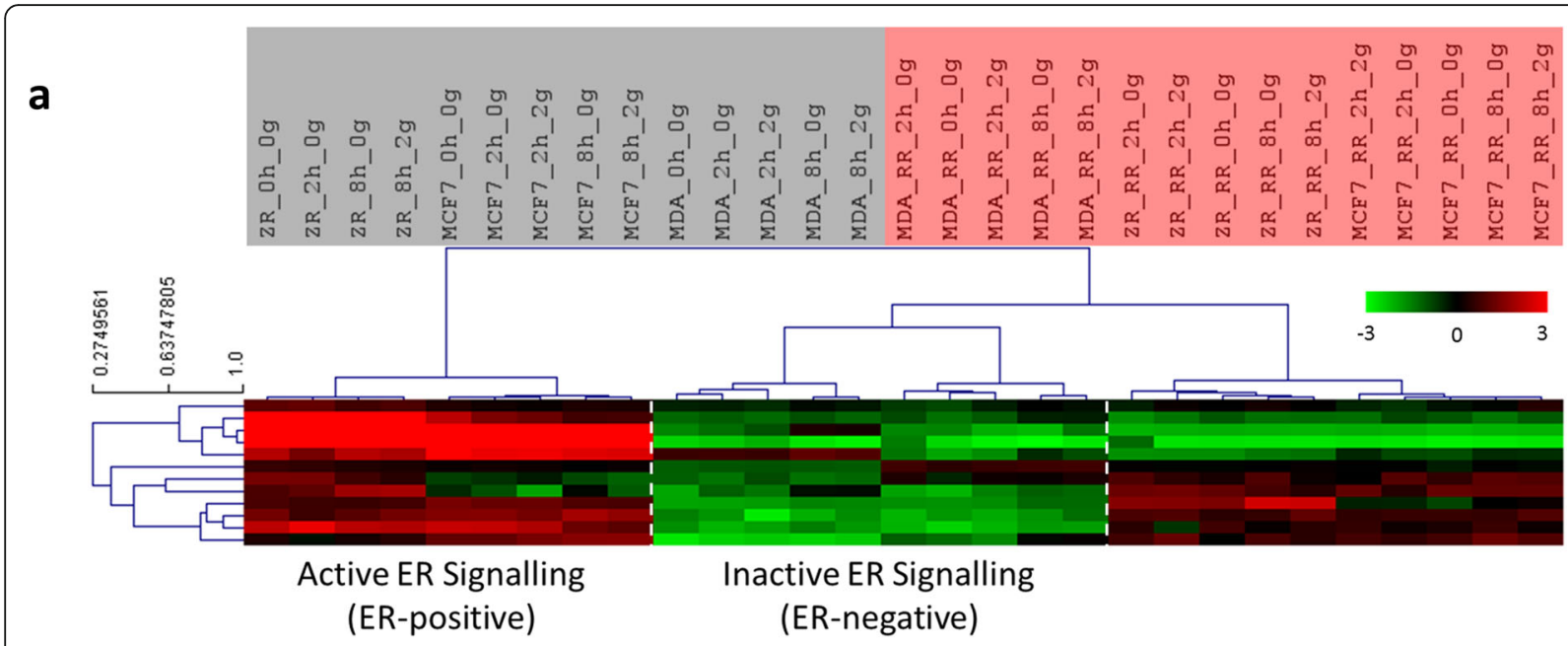

b

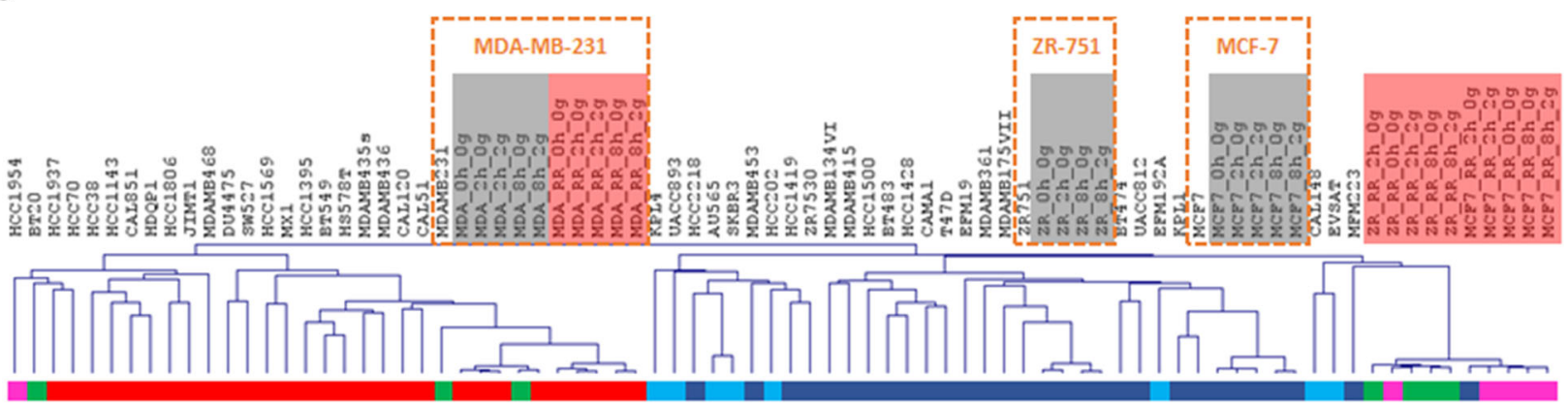

Fig. 7 ER+ derived radioresistant cell lines exhibited a change in oestrogen signalling associated genes and a change in intrinsic breast cancer subtyping. a Heatmap showing log2 mean-centered expression profile of a published oestrogen-signalling gene signature [26]; red = higher expression, green = lower expression. Heatmap clustering was carried out using Pearson correlation with average linkage. b Study data was integrated with a public gene expression dataset (GSE50811) of 67 breast cancer cell lines. Hierarchical clustering of parental and RR cell lines based on Pearson correlation to centroids of Sørlie 2003 intrinsic genes [16]; Red = Basal, Dark blue = Luminal A, Light blue = Luminal B,

Purple $=$ HER2-overexpressing, Green $=$ Normal-like

study that showed radioresistant MCF-7 cells lost their resistant phenotype 12 weeks after a final dose of radiation [29]. The difference in maintenance of the RR phenotype could be due to our cell lines being exposed to radiation over a longer time period, which could contribute to more stable phenotypic changes and highlights the importance of performing regular CF/SRB assays to confirm the maintenance of radioresistance.

Only a small number of other studies have investigated mechanisms of acquired RR through the generation of RR cell lines, which tend to focus on a single specific pathway [7, 29-33]. Reduced proliferation rates have been identified in RR cell lines [34]; reduced proliferation in our MCF-7 RR and ZR-751 RR cell lines was reflected in the gene expression profiles and reduced Ki67 expression in MTS. One study used 3 prostate cancer cell lines (androgen responsive and non-responsive) to develop RR derivates; they identified enhanced EMT/ cancer stem cell phenotypes and activation of checkpoint proteins and $\mathrm{PI} 3 \mathrm{~K} / \mathrm{AKT} / \mathrm{mTOR}$ signalling pathways in the RR cells [31]. Our study took a similar approach by using 3 breast cancer cell lines, $2 \mathrm{ER}+$ and hormone responsive (MCF-7 and ZR-751) and 1 ERand hormone non-responsive (MDA-MB-231). However, our approach was more global and investigated multiple potential radioresistance mechanisms rather than focusing on individual pathways.

Among breast cancer patients, more than $90 \%$ of cancer related deaths are from metastatic rather than primary disease [35]; further understanding of breast cancer metastasis and treatment failure is therefore of clinical importance. We identified that the MCF-7 RR and ZR-751 RR cell lines had increased invasion and migration ability compared with their parental cell lines whereas the MDA-MB-231 RR cell line exhibited increased migration but had only a marginal, non-significant increase in invasion compared to the parental cells. The results suggest that these RR cell lines developed a more aggressive phenotype, which was more pronounced in the ER+ derived RR cell lines, 


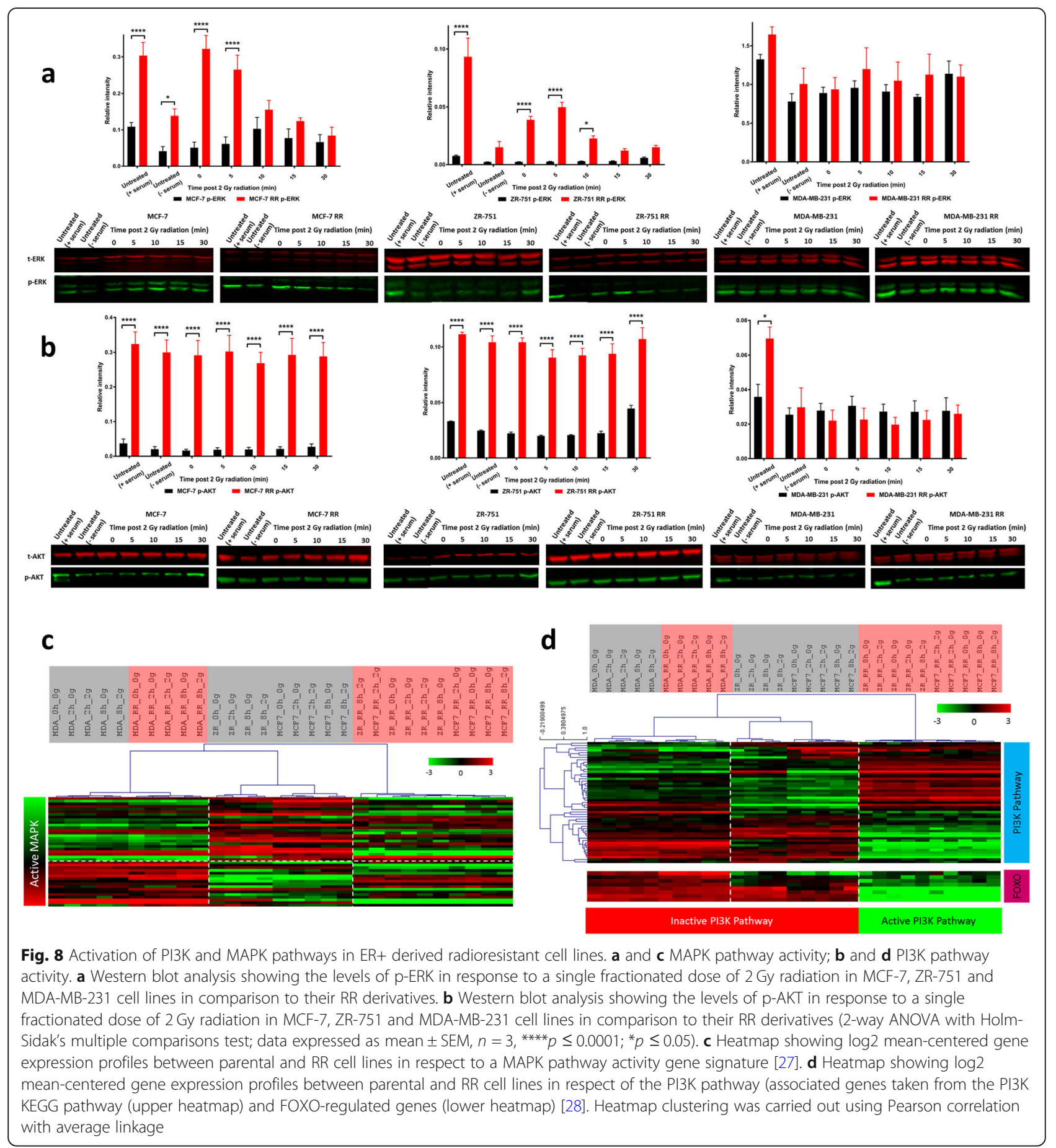

which clinically could lead to a greater potential for metastasis.

To model this further we used well established MTS models that more accurately represent the tumour microenvironment within a solid tumour; MTS exhibit 3D cell-cell interactions and can develop $\mathrm{O}_{2}$, nutrient and catabolite gradients, producing a central necrotic core and outer proliferating layer of cells [36].
The novel MTS derived from RR cells developed in this study serve as excellent tumour models of radioresistance to investigate invasiveness and protein expression through IHC, which aided in their classification.

EMT is an important process in malignant transformation that leads to reduced cell-cell contacts, increased cell motility and metastasis [37-39]. Loss of epithelial morphology is an important prognostic indicator that 
correlates with worse prognosis [40]. Hybrid/intermediate phenotypes show the ability of cancer cells to undergo EMT and mesenchymal-to-epithelial-transition, thus traversing the epithelial and mesenchymal states [38]. In our RR model we demonstrated a down regulation of E-cadherin and upregulation of vimentin, $\mathrm{N}$-cadherin and SNAIL, all known biomarkers for EMT in breast cancer [41], in the MCF-7 RR and ZR-751 RR cell lines. These results support the morphological and functional changes in RR cells, which developed a more mesenchymal-like phenotype with increased invasive and migratory potential. The MDA-MB-231 cell line has previously been characterised as having a mesenchymallike phenotype with constitutively low E-cadherin and high vimentin expression, so any further development of EMT in its RR derivative was difficult to ascertain. Many signalling pathways can activate EMT in both normal and cancer cells, including receptor tyrosine kinase signalling, TGF $\beta$, Wnt- $\beta$-catenin and Notch signalling [42, 43]; radiation alone can also induce EMT through the expression of TGF $\beta[44,45]$. Both EGFR downstream signalling pathways and Wnt signalling were found to be activated in our MCF-7 RR and ZR-751 RR cell lines suggesting possible mechanisms by which the cells underwent EMT. It is interesting to note that the same population of cells, predominantly those around the periphery of the MTS formed from ER+ RR cells, showed increased co-expression of vimentin, Snail, N-cadherin and WNT5a.

Breast cancer is routinely characterised immunohistochemically by the expression of receptors such as HER2, $E R \alpha, \operatorname{PgR}$ and EGFR; gene expression profiling can also be used to identify molecular characteristics of breast cancer cells and classify them into 5 specific subtypes with distinct clinical outcomes: luminal A, luminal B, HER2-overexpressing, basal and normal-like tumours $[46,47]$. These different breast cancer subtypes have also been shown to exhibit differential inherent sensitivities to ionising radiation and reflect prognosis [48, 49]. The clinical usefulness of molecular subtyping of cell lines has been previously investigated through comparing the genomic and transcriptional characteristics of breast cancer cell lines with that of primary breast tumours. One study showed that recurrent genome aberrations and the resulting transcriptional changes identified in 51 cell lines (including MDA-MB-231, MCF-7 and ZR-751) were well preserved in comparison to those found in primary tumours of a similar classification and that cell lines may not accumulate substantial new mutations during extended culture, showing stable genomic patterns over multiple passages [50]. Although the cell lines carried more genome aberrations, possibly related to some cell lines having been derived from late stage tumours or pleural effusions, they concluded that cell lines were well suited to assess the functional consequences of genome-aberrations-mediated gene deregulation and to identify molecular features that predict resistance/ sensitivity to agents targeting these aberrations. However, it is important to note that cell line expression profiles will not account for the tumour microenvironment including normal epithelial cells or stromal tissue, nor will they reflect intra-tumoural heterogeneity. With these caveats in mind the purpose of subtyping in this study was to demonstrate that the development of radioresistance is consistent with a change to a prognostically less favourable intrinsic subtype.

In our study the transcriptional profiles of parental and RR cell lines were assigned to intrinsic breast cancer subtypes. Both the MDA-MB-231 parental and RR cell lines were triple negative, and subtyping identified them as basal $[16,46,51,52]$. As the MDA-MB-231 parental cell line is inherently aggressive, it is not surprising that no significant changes were identified in its RR derivative. However, a change in classification was identified in RR cell lines derived from ER+ cells, with a shift from luminal A for both MCF-7 and ZR-751 cell lines towards a non-luminal classification. The MCF-7 RR cell line was most closely correlated to the HER2-overexpressing subtype while the ZR-751 RR cell line was more closely correlated to the normal-like subtype. Both HER2-overexpressing and normal-like subtypes carry a worse prognosis compared to luminal A tumours, with HER2-overexpressing tumours having a higher risk of locoregional recurrence $[16,46,51,52]$. Luminal A tumours also respond well to hormone and radiation treatment [51], and a shift away from this subtype would therefore be consistent with a loss of radiosensitivity, resistance to endocrine therapy and a more aggressive phenotype. These results show that the acquisition of radioresistance can be linked with cellular plasticity through extensive alterations in gene expression resulting in a change in molecular subtype.

Analysis of protein expression indicated that both MCF-7 RR and ZR-751 RR cell lines lost both ER $\alpha$ and PgR expression and gained EGFR expression. Furthermore, ER $\alpha$ siRNA knockdown resulted in increased EGFR protein expression in the MCF-7 cell line, suggesting a direct relationship between loss of ER $\alpha$ and increased EGFR expression. Using gene analysis, we further identified that ER driven genes had lower expression in the RR cell lines derived from ER+ cell lines. An inverse relationship between ER activity and EGFR and HER2 expression has been reported in clinical breast cancer, with overexpression of these receptor tyrosine kinases being associated with decreased sensitivity to endocrine therapy and a poorer prognosis [53-55]. An apparent switch from ER signalling to EGFR-mediated signalling was investigated by the treatment of MCF-7 
and MCF-7 RR cells with the EGFR inhibitor gefitinib and the anti-oestrogen tamoxifen.

Gefitinib produced a greater concentration-dependent reduction in cell proliferation in the MCF-7 RR cell line with an $\mathrm{IC}_{50}$ value of $6.43 \mu \mathrm{M}$. This is a relatively high concentration compared to clinically relevant doses [56-58]; however, while this suggests the MCF-7 RR cell line is relatively insensitive to the effects of gefitinib, there was a significant reduction in the $\mathrm{IC}_{50}$ value from $13.34 \mu \mathrm{M}$ for the MCF-7 parental cell line. Results also showed that the RR cells developed simultaneous resistance to tamoxifen at clinically relevant doses. Tamoxifen may be given to patients with ER+ breast cancer for 3-5 years following surgery and radiotherapy; if radioresistant cells remain following a patient's RT course then the efficacy of tamoxifen in radioresistant cells needs to be assessed. Mechanisms for acquired tamoxifen resistance are complex since tamoxifen resistant tumours usually do not lose ER $\alpha$ [59], with the receptor still remaining functional as demonstrated by cohorts of patients with recurrent disease still being able to respond to secondary endocrine therapy $[60,61]$. This has led to studies suggesting that tamoxifen resistance is through modification of ER functionality by growth factor pathways $[62,63]$. A previous study using MCF-7 RR cells demonstrated resistance to tamoxifen without a change in ER expression. However, AKT phosphorylation was increased and the investigators suggested that sequential tamoxifen treatment following radiation could be more effective than concurrent treatment [33]. Conversely, results from our study showed that when radiation was delivered $24 \mathrm{~h}$ after tamoxifen treatment or ER $\alpha$ knockdown in the MCF-7 cells, an additional decrease in proliferation was observed, suggesting that the use of tamoxifen before and during a patient's RT treatment may be advantageous. Another study determined that tamoxifen-resistant MCF-7 cells, showed enhanced sensitivity to EGF and oestradiol stimulation. Although ER $\alpha$ was not lost, it was found to redistribute to extra-nuclear sites (cytoplasmic translocation) in the tamoxifen-resistant cells and they suggested that enhanced ER $\alpha$ function, via cooperation with EGFR, is one mechanism responsible for acquired tamoxifen resistance [64]. Similar results have also been shown with the establishment of anti-oestrogen-resistant MCF-7 cells, developed through continuous culture in fulvestrant (trade name Faslodex). These resistant cells developed reduced ER $\alpha$ expression and loss of PgR with increased dependence on EGFR/MAPK mediated signalling [65]. Our radioresistant model has shown that ER $\alpha$ and PgR loss occurs with concurrent resistance to tamoxifen which may involve different pathways compared to the development of tamoxifen resistance from chronic drug exposure. This suggests that additional targeted therapy may be required in these cells.
Because total EGFR expression was significantly increased in the RR cell lines, the downstream signal transduction pathways of the HER tyrosine-kinase receptor family were further investigated.

The phosphatidylinositol-3-kinase (PI3-k)/protein kinase $B(A K T)$ cascade is frequently overactive in a wide range of cancers and can trigger a cascade of responses related to cell survival and metabolism [66, 67]. It is also activated by RT and has been associated with resistance mechanisms such as intrinsic radioresistance, tumour cell proliferation and hypoxia $[68,69]$. In this study we found that the gene expression signature in the MCF-7 RR and ZR-751 RR cell lines fitted with activation of the PI3K pathway. Although p-AKT did not increase in response to radiation, its levels were statistically higher than in the parental derivatives, suggesting that the PI3K/AKT/ mTOR signalling pathway is activated in these RR cell lines and may play an important role in radioresistance.

In breast and other cancers radiation-induced proliferation has been linked with activation of EGFR and downstream components of the mitogen-activated protein kinase (MAPK) cascade, including phospholipase-C, Ras, and Raf-1 [70-73] and can be considered an important cytoprotective response [74]. MAKP activation may represent a mechanism by which cancer cells can cause tumour repopulation during fractionated RT courses. Results from this study at the gene and protein level suggest that MAPK signalling is activated in the MCF-7 RR and ZR-751 RR cell lines since basal levels of p-ERK1 and p-ERK2 were significantly higher than in their parental cell lines and phosphorylation of ERK1 and ERK2 occurred almost immediately following a 2 Gy radiation dose. This radiation-induced phosphorylation occurred more quickly and to a larger extent than in the parental cell lines. Our results suggest that EGFR signalling, and multiple components of its downstream pathways are activated in the MCF-7 RR and ZR-751 RR cell lines, which could have significant clinical implications, as multiple pathways may need to be targeted to improve the therapeutic response to irradiation.

The use of multiple techniques ranging from gene to protein to functional experiments, which led to the validation of our results through independent means, represents one of the main strengths of this study. Additionally, the development of ER+ and ER- RR cell lines allowed for comparisons to be made between different molecular breast cancer subtypes. The aim of our study was to characterise these RR cell lines and identify pathways that could be related to radioresistance, rather than focusing on the reversal of radioresistance itself. However, following our successful characterisation, we now aim to use these cell lines in future studies to target these identified pathways and to identify biomarkers (genetic and secretomic signatures) that could be used 
for determining radiosensitivity and for the assessment of a tumour's response to radiotherapy.

\section{Conclusion}

In this study we developed a novel model to help improve the understanding and characterisation of radioresistant breast cancer cells and identified several important and likely interrelated networks contributing to the development of radioresistance. ER+ derived RR cell lines were characterised by a shift towards a more invasive mesenchymal phenotype with changes in oestrogen regulation, gain of EGFR signalling and change in subtype classification. The ER- cell line possessed these characteristics at the outset and hence its phenotype changed relatively little with the development of radioresistance. Here we have begun to dissect the mechanisms and signalling pathways involved in the development of radioresistance. Models of resistant disease as developed and examined in this study will be instrumental in future research and will aid the development of new therapeutic strategies for patients that either fail to respond or develop recurrent disease.

\section{Additional files}

Additional file 1: Table S1. RIN values for all samples used in gene expression analysis. (XLSX $10 \mathrm{~kb}$ )

Additional file 2: Table S2. Overview of samples (cell line, treatments, time points, replicates) used in each experiment or analysis. (XLSX $15 \mathrm{~kb}$ )

Additional file 3: Figure S1. Colony formation assay comparing MCF-7, MCF-7 RR and MCF-7 rr (radioresistant cell line not radiated for 6 months (24 passages)) cell lines. (TIF $51 \mathrm{~kb}$ )

Additional file 4: Figure S2. ICC and IHC staining of EMT markers in ZR-751 parental and RR cell lines. (TIF $2384 \mathrm{~kb}$ )

Additional file 5: Figure S3. ICC and IHC staining of EMT markers in MCF-7 parental and RR cell lines. (TIF 2391 kb)

Additional file 6: Table S3. Gene lists from a published EMT signature [23] and WNT signalling associated genes [25] applied to our gene expression data. (XLS $62 \mathrm{~kb}$ )

Additional file 7: Figure S4. ICC and IHC staining for signalling receptors in ZR-751 parental and RR cell lines. (TIF 2818 kb)

Additional file 8: Figure S5. ICC and IHC staining for signalling receptors in MCF-7 parental and RR cell lines. (TIF 2708 kb)

Additional file 9: Figure S6. (A) SRB at $72 \mathrm{~h}$ and (B) Scratch assay at $24 \mathrm{~h}$ showing the effects of gefitinib on ZR-751 and ZR-751 RR cell lines (2-way ANOVA with Holm-Sidak's multiple comparisons test; data expressed as mean \pm SEM $\left., n=3,{ }^{* * * *} p \leq 0.0001 ;{ }^{* * *} p \leq 0.001 ;{ }^{* *} p \leq 0.01 ;{ }^{*} p \leq 0.05\right)$. (TIF $170 \mathrm{~kb}$ )

Additional file 10: Figure S7. Gene expression heatmap based on Pearson correlation hierarchical clustering with average linkage using a published list of intrinsic subtype genes [16]. Intrinsic subtype was assigned using the genefu R package Single Sample Predictor (SSP) algorithm [17]; red=higher expression, green=lower expression. Red=Basal, Dark blue $=$ Luminal A, Light blue $=$ Luminal B, Purple=HER2overexpressing, Green=Normal-like. (TIF 758 kb)

\section{Abbreviations}

ATP: Adenosine triphosphate; BCA: Bicinchoninic acid; BCS: Breast conserving surgery; CF: Colony formation; DMEM: Dulbecco's modified Eagle's medium; DNA: Deoxyribonucleic acid; DSB: Double strand break; EGFR: Epidermal growth factor receptor; EMT: Epithelial-to-mesenchymal transition; ER: Oestrogen receptor; ERK1/2: Extracellular-signal regulated kinases 1 and 2;
FCS: Foetal calf serum; HER2: Human epidermal growth factor receptor 2; ICC: Immunocytochemistry; IHC: Immunohistochemistry; KEGG: Kyoto Encyclopaedia of Genes and Genomes; MAPK: Mitogen-activated protein kinase; MTS: Multicellular tumour spheroid; NF-kB: Nuclear factor kappa light chain enhancer of activated B cells; PgR: Progesterone receptor; PI3K: Phosphatidylinositol-4,5-bisphosphate 3-kinase; RNA: Ribonucleic acid; RR: Radioresistant; RT: Radiotherapy; RTK: Receptor tyrosine kinase; SRB: Sulforhodamine B; TGF $\beta$ : Transforming growth factor beta; WNT: Wingless-related integration site

\section{Acknowledgements}

Not applicable.

\section{Funding}

This work was supported by funding from the UK Engineering and Physical Sciences Research Council, through the IMPACT programme grant (EP/K-34510/1).

Availability of data and materials

The datasets generated and/or analysed during the current study are available in the NCBI's Gene Expression Omnibus [18] and are accessible through GEO Series accession number GSE120798.

\section{Authors' contributions}

MG conceptualised, performed, analysed and interpreted the majority of the laboratory work and was a major contributor in writing the manuscript. AT performed all bioinformatic analysis and was a major contributor in writing the manuscript. JM performed some of the invasion and ICC assays. MB performed some of the migration assays. All authors read and approved the final manuscript.

\section{Authors' information}

Not applicable.

Ethics approval and consent to participate

Not applicable.

Consent for publication

Not applicable.

Competing interests

The authors declare that they have no competing interests.

\section{Publisher's Note}

Springer Nature remains neutral with regard to jurisdictional claims in published maps and institutional affiliations.

\section{Author details}

${ }^{1}$ The Royal (Dick) School of Veterinary Studies and Roslin Institute, University of Edinburgh, Edinburgh, Scotland. ${ }^{2}$ Cancer Research UK Edinburgh Centre and Division of Pathology Laboratories, Institute of Genetics and Molecular Medicine, Western General Hospital, University of Edinburgh, Edinburgh, Scotland. ${ }^{3}$ Breast Cancer Now Edinburgh Research Team, Institute of Genetics and Molecular Medicine, Western General Hospital, University of Edinburgh, Edinburgh, Scotland. ${ }^{4}$ Institute of Sensors, Signals and Systems, School of Engineering and Physical Sciences, Heriot-Watt University, Edinburgh, Scotland. 5 School of Engineering, Faraday Building, The King's Buildings, University of Edinburgh, Edinburgh, Scotland.

Received: 19 October 2018 Accepted: 2 April 2019 Published online: 15 April 2019

References

1. Delaney G, Jacob S, Featherstone C, Barton M. The role of radiotherapy in cancer treatment: estimating optimal utilization from a review of evidencebased clinical guidelines. Cancer. 2005;104(6):1129-37.

2. Onitilo AA, Engel JM, Stankowski RV, Doi SA. Survival comparisons for breast conserving surgery and mastectomy revisited: community experience and the role of radiation therapy. Clin Med Res. 2015;13(2):65-73.

3. Cao JQ, Olson RA, Tyldesley SK. Comparison of recurrence and survival rates after breast-conserving therapy and mastectomy in young women with breast cancer. Curr Oncol (Toronto, Ont). 2013;20(6):e593-601. 
4. Poortmans P. Evidence based radiation oncology: breast cancer. Radiother Oncol. 2007;84(1):84-101.

5. Barker HE, Paget JTE, Khan AA, Harrington KJ. The tumour microenvironment after radiotherapy: mechanisms of resistance and recurrence. Nat Rev Cancer. 2015;15(7):409-25.

6. Keith B, Simon MC. Hypoxia inducible factors, stem cells and cancer. Cell. 2007;129(3):465-72.

7. Smith L, Qutob O, Watson MB, Beavis AW, Potts D, Welham KJ, Garimella V, Lind MJ, Drew PJ, Cawkwell L. Proteomic identification of putative biomarkers of radiotherapy resistance: a possible role for the $26 \mathrm{~S}$ proteasome? Neoplasia. 2009;11(11):1194-207.

8. Franken NA, Rodermond HM, Stap J, Haveman J, Van Bree C. Clonogenic assay of cells in vitro. Nat Protoc. 2006;1(5):2315.

9. Liang C-C, Park AY, Guan J-L. In vitro scratch assay: a convenient and inexpensive method for analysis of cell migration in vitro. Nat Protoc. 2007; 2:329-33.

10. Meehan J, Ward C, Turnbull A, Bukowski-Wills J, Finch AJ, Jarman EJ, Xintaropoulou C, Martinez-Perez C, Gray M, Pearson M. Inhibition of pH regulation as a therapeutic strategy in hypoxic human breast cancer cells. Oncotarget. 2017;8(26):42857-75.

11. Dobin A, Davis CA, Schlesinger F, Drenkow J, Zaleski C, Jha S, Batut P, Chaisson M, Gingeras TR. STAR: ultrafast universal RNA-seq aligner. Bioinformatics. 2013;29(1):15-21.

12. Gentleman RC, Carey VJ, Bates DM, Bolstad B, Dettling M, Dudoit S, Ellis B, Gautier L, Ge Y, Gentry J. Bioconductor: open software development for computational biology and bioinformatics. Genome Biol. 2004;5(10):80-96.

13. Howe E, Holton K, Nair S, Schlauch D, Sinha R, Quackenbush J. MeV: MultiExperiment viewer. In: Ochs MF, Casagrande JT, Davuluri RV, editors. Biomedical informatics for cancer research. Boston: Springer US; 2010. p. 267-77.

14. Leek JT, Johnson WE, Parker HS, Jaffe AE, Storey JD. The sva package for removing batch effects and other unwanted variation in high-throughput experiments. Bioinformatics. 2012;28(6):882-3.

15. Turnbull AK, Kitchen RR, Larionov AA, Renshaw L, Dixon JM, Sims AH. Direct integration of intensity-level data from Affymetrix and Illumina microarrays improves statistical power for robust reanalysis. BMC Med Genet. 2012;5(1):5-35

16. Sørlie T, Tibshirani R, Parker J, Hastie T, Marron JS, Nobel A, Deng S, Johnsen $H$, Pesich R, Geisler S. Repeated observation of breast tumor subtypes in independent gene expression data sets. Proc Natl Acad Sci. 2003;100(14): 8418-23.

17. Gendoo DM, Ratanasirigulchai N, Schröder MS, Paré L, Parker JS, Prat A, Haibe-Kains B. Genefu: an R/Bioconductor package for computation of gene expression-based signatures in breast cancer. Bioinformatics. 2015;32(7): 1097-9.

18. Edgar R, Domrachev M, Lash AE. Gene expression omnibus: NCBI gene expression and hybridization array data repository. Nucleic Acids Res. 2002; 30(1):207-10.

19. Bankhead P, Loughrey MB, Fernandez JA, Dombrowski Y, McArt DG, Dunne PD, McQuaid S, Gray RT, Murray LJ, Coleman HG, et al. QuPath: open source software for digital pathology image analysis. Sci Rep. 2017;7(1):16878-85.

20. Thiery JP, Sleeman JP. Complex networks orchestrate epithelialmesenchymal transitions. Nat Rev Mol Cell Biol. 2006;7(2):131-42.

21. Sarrio D, Franklin CK, Mackay A, Reis-Filho JS, Isacke CM. Epithelial and mesenchymal subpopulations within normal basal breast cell lines exhibit distinct stem cell/progenitor properties. Stem Cells. 2012;30(2):292-303.

22. Thiery JP. Epithelial-mesenchymal transitions in tumour progression. Nat Rev Cancer. 2002;2(6):442.

23. Rokavec M, Kaller M, Horst D, Hermeking H. Pan-cancer EMT-signature identifies RBM47 down-regulation during colorectal cancer progression. Sci Rep. 2017;7(1):4687-702.

24. Theys J, Jutten B, Habets R, Paesmans K, Groot AJ, Lambin P, Wouters BG, Lammering G, Vooijs M. E-cadherin loss associated with EMT promotes radioresistance in human tumor cells. Radiother Oncol. 2011:99(3):392-7.

25. Ogata H, Goto S, Sato K, Fujibuchi W, Bono H, Kanehisa M. KEGG: Kyoto encyclopedia of genes and genomes. Nucleic Acids Res. 1999;27(1):29-34.

26. Verhaegh $W$, van Ooijen $H$, Inda MA, Hatzis $P$, Versteeg $R$, Smid M, Martens $J$, Foekens J, van de Wiel P, Clevers $\mathrm{H}$, et al. Selection of personalized patient therapy through the use of knowledge-based computational models that identify tumor-driving signal transduction pathways. Cancer Res. 2014;74(11):2936-45.
27. Creighton CJ, Hilger AM, Murthy S, Rae JM, Chinnaiyan AM, El-Ashry D. Activation of mitogen-activated protein kinase in estrogen receptor apositive breast Cancer cells in vitro induces an in vivo molecular phenotype of estrogen receptor a-negative human breast tumors. Cancer Res. 2006; 66(7):3903-11.

28. van Ooijen $H$, Hornsveld M, Dam-de Veen C, Velter R, Dou M, Verhaegh W, Burgering B, van de Stolpe A. Assessment of functional phosphatidylinositol 3-kinase pathway activity in Cancer tissue using Forkhead box $\mathrm{O}$ target gene expression in a knowledge-based computational model. Am J Pathol. 2018;188:1956-72.

29. Li Z, Xia L, Lee LM, Khaletskiy A, Wang J, Wong JY, Li J-J. Effector genes altered in MCF-7 human breast cancer cells after exposure to fractionated ionizing radiation. Radiat Res. 2001;155(4):543-53.

30. Wang T, Tamae D, LeBon T, Shively JE, Yen Y, Li JJ. The role of peroxiredoxin II in radiation-resistant MCF-7 breast cancer cells. Cancer Res. 2005;65(22): 10338-46.

31. Chang L, Graham PH, Hao J, Ni J, Bucci J, Cozzi PJ, Kearsley JH, Li Y, Chang Y, Graham Y, et al. Acquisition of epithelialmesenchymal transition and cancer stem cell phenotypes is associated with activation of the Pl3K/Akt/mTOR pathway in prostate cancer radioresistance. Cell Death Dis. 2013;4(10):875-90.

32. Shimura T, Noma N, Sano Y, Ochiai Y, Oikawa T, Fukumoto M, Kunugita N. AKT-mediated enhanced aerobic glycolysis causes acquired radioresistance by human tumor cells. Radiother Oncol. 2014;112(2):302-7.

33. Jang H, Baek J, Nam K-S, Kim S. Determination of the optimal time for tamoxifen treatment in combination with radiotherapy. Int J Oncol. 2016; 49(5):2147-54.

34. Chang L, Ni J, Beretov J, Wasinger VC, Hao J, Bucci J, Malouf D, Gillatt D, Graham PH, Li Y. Identification of protein biomarkers and signaling pathways associated with prostate cancer radioresistance using label-free LC-MS/MS proteomic approach. Sci Rep. 2017;7:41834-48.

35. DeSantis C, Siegel R, Bandi P, Jemal A. Breast cancer statistics, 2011. CA Cancer J Clin. 2011;61(6):408-18.

36. Hirschhaeuser F, Menne H, Dittfeld C, West J, Mueller-Klieser W, KunzSchughart LA. Multicellular tumor spheroids: an underestimated tool is catching up again. J Biotechnol. 2010;148(1):3-15.

37. Pinto CA, Widodo E, Waltham M, Thompson EW. Breast cancer stem cells and epithelial mesenchymal plasticity - implications for chemoresistance. Cancer Lett. 2013;341(1):56-62.

38. Lee JM, Dedhar S, Kalluri R, Thompson EW. The epithelial-mesenchymal transition: new insights in signaling, development, and disease. J Cell Biol. 2006;172(7):973-81.

39. Thompson EW, Newgreen DF. Carcinoma invasion and metastasis: a role for epithelial-mesenchymal transition? Cancer Res. 2005;65(14):5991-5.

40. Sommers CL, Heckford SE, Skerker JM, Worland P, Torri JA, Thompson EW, Byers SW, Gelmann EP. Loss of epithelial markers and acquisition of vimentin expression in adriamycin-and vinblastine-resistant human breast cancer cell lines. Cancer Res. 1992:52(19):5190-7.

41. Liu F, Gu LN, Shan BE, Geng CZ, Sang MX. Biomarkers for EMT and MET in breast cancer: an update. Oncol Lett. 2016:12(6):4869-76.

42. Yook JI, Li X-Y, Ota I, Fearon ER, Weiss SJ. Wnt-dependent regulation of the E-cadherin repressor Snail. J Biol Chem. 2005;280(12):11740-8.

43. Thiery JP, Acloque H, Huang RY, Nieto MA. Epithelial-mesenchymal transitions in development and disease. Cell. 2009;139(5):871-90.

44. Zhou Y-C, Liu J-Y, Li J, Zhang J, Xu Y-Q, Zhang H-W, Qiu L-B, Ding G-R, Su $X-M, M e i \mathrm{~S}$, et al. lonizing radiation promotes migration and invasion of Cancer cells through transforming growth factor-Beta-mediated epithelialmesenchymal transition. Int J Radiat Oncol Biol Phys. 2011;81(5):1530-7.

45. Andarawewa KL, Erickson AC, Chou WS, Costes SV, Gascard P, Mott JD, Bissell MJ, Barcellos-Hoff MH. lonizing radiation predisposes nonmalignant human mammary epithelial cells to undergo transforming growth factor beta induced epithelial to mesenchymal transition. Cancer Res. 2007;67(18):8662-78.

46. Sørlie T, Perou CM, Tibshirani R, Aas T, Geisler S, Johnsen H, Hastie T, Eisen $M B$, Van De Rijn M, Jeffrey SS. Gene expression patterns of breast carcinomas distinguish tumor subclasses with clinical implications. Proc Natl Acad Sci. 2001;98(19):10869-74.

47. Perou CM, Sørlie T, Eisen MB, Van De Rijn M, Jeffrey SS, Rees CA, Pollack JR, Ross DT, Johnsen H, Akslen LA. Molecular portraits of human breast tumours. Nature. 2000;406(6797):747-52.

48. Kyndi M, Sørensen FB, Knudsen H, Overgaard M, Nielsen HM, Overgaard J. Estrogen receptor, progesterone receptor, HER-2, and response to 
postmastectomy radiotherapy in high-risk breast cancer: the Danish breast Cancer cooperative group. J Clin Oncol. 2008;26(9):1419-26.

49. Wang $Y$, Yin $Q$, Yu Q, Zhang J, Liu Z, Wang S, Lv S, Niu Y. A retrospective study of breast cancer subtypes: the risk of relapse and the relations with treatments. Breast Cancer Res Treat. 2011;130(2):489.

50. Neve RM, Chin K, Fridlyand J, Yeh J, Baehner FL, Fevr T, Clark L, Bayani N, Coppe J-P, Tong F, et al. A collection of breast cancer cell lines for the study of functionally distinct cancer subtypes. Cancer Cell. 2006;10(6):515-27.

51. Dai X, Li T, Bai Z, Yang Y, Liu X, Zhan J, Shi B. Breast cancer intrinsic subtype classification, clinical use and future trends. Am J Cancer Res. 2015;5(10):2929-43.

52. Sotiriou C, Neo S-Y, MCShane LM, Korn EL, Long PM, Jazaeri A, Martiat P, Fox SB, Harris AL, Liu ET. Breast cancer classification and prognosis based on gene expression profiles from a population-based study. Proc Natl Acad Sci. 2003;100(18):10393-8.

53. Nicholson RI, McClelland RA, Gee JMW, Manning DL, Cannon P, Robertson JFR, Ellis IO, Blamey RW. Epidermal growth factor receptor expression in breast cancer: association with response to endocrine therapy. Breast Cancer Res Treat. 1994;29(1):117-25.

54. Nicholson RI, McClelland RA, Finlay P, Eaton CL, Gullick WJ, Dixon AR, Robertson JFR, Blamey RW, Ellis IO. Relationship between EGF-R, c-erbB-2 protein expression and Ki67 immunostaining in breast cancer and hormone sensitivity. Eur J Cancer. 1993;29(7):1018-23.

55. Wright C, Nicholson S, Angus B, Sainsbury J, Farndon J, Cairns J, Harris A, Horne C. Relationship between c-erbB-2 protein product expression and response to endocrine therapy in advanced breast cancer. Br J Cancer. 1992;65(1):118-21.

56. Huang S, Armstrong EA, Benavente S, Chinnaiyan P, Harari PM. Dual-agent molecular targeting of the epidermal growth factor receptor (EGFR): combining anti-EGFR antibody with tyrosine kinase inhibitor. Cancer Res. 2004;64(15):5355-62.

57. Erjala K, Raitanen M, Kulmala J, Grénman R. Concurrent use of vinorelbine and gefitinib induces supra-additive effect in head and neck squamous cell carcinoma cell lines. J Cancer Res Clin Oncol. 2007;133(3):169-76.

58. Sharma SV, Bell DW, Settleman J, Haber DA. Epidermal growth factor receptor mutations in lung cancer. Nat Rev Cancer. 2007;7(3):169-81.

59. Gutierrez MC, Detre S, Johnston S, Mohsin SK, Shou J, Allred DC, Schiff R, Osborne CK, Dowsett M. Molecular changes in tamoxifen-resistant breast cancer: relationship between estrogen receptor, HER-2, and p38 mitogenactivated protein kinase. J Clin Oncol. 2005;23(11):2469-76.

60. Encarnación CA, Ciocca DR, McGuire WL, Clark GM, Fuqua SA, Osborne CK. Measurement of steroid hormone receptors in breast cancer patients on tamoxifen. Breast Cancer Res Treat. 1993;26(3):237-46.

61. Brünner N, Frandsen TL, Holst-Hansen C, Bei M, Thompson EW, Wakeling AE, Lippman ME, Clarke R. MCF7/LCC2: a 4-hydroxytamoxifen resistant human breast cancer variant that retains sensitivity to the steroidal antiestrogen $\mid \mathrm{Cl}$ 182,780. Cancer Res. 1993;53(14):3229-32.

62. Long B, McKibben B, Lynch M, Van den Berg H. Changes in epidermal growth factor receptor expression and response to ligand associated with acquired tamoxifen resistance or oestrogen independence in the ZR-75-1 human breast cancer cell line. Br J Cancer. 1992:65(6):865-9.

63. Nicholson Rl, Gee JMW. Oestrogen and growth factor cross-talk and endocrine insensitivity and acquired resistance in breast cancer. $\mathrm{Br} J$ Cancer. 2000;82(3):501-13.

64. Fan P, Wang J, Santen RJ, Yue W. Long-term treatment with tamoxifen facilitates translocation of estrogen receptor a out of the nucleus and enhances its interaction with EGFR in MCF-7 breast cancer cells. Cancer Res. 2007;67(3):1352-60.

65. McClelland RA, Barrow D, Madden T-A, Dutkowski CM, Pamment J, Knowlden JM, Gee JM, Nicholson RI. Enhanced epidermal growth factor receptor signaling in MCF7 breast cancer cells after long-term culture in the presence of the pure antiestrogen ICI 182,780 (Faslodex). Endocrinology. 2001;142(7):2776-88

66. Shimura T, Noma N, Oikawa T, Ochiai Y, Kakuda S, Kuwahara Y, Takai Y, Takahashi A, Fukumoto M. Activation of the AKT/cyclin D1/Cdk4 survival signaling pathway in radioresistant cancer stem cells. Oncogenesis. 2012; 1(6):12-20.

67. Shimura T, Kakuda S, Ochiai Y, Nakagawa H, Kuwahara Y, Takai Y, Kobayashi J, Komatsu K, Fukumoto M. Acquired radioresistance of human tumor cells by DNA-PK/AKT/GSK3B-mediated cyclin D1 overexpression. Oncogene. 2010;29(34):4826-37.
68. Igor V, Charles LS. The phosphatidylinositol 3-kinase-AKT pathway in human cancer. Nat Rev Cancer. 2002;2(7):489-501.

69. Liang K, Jin W, Knuefermann C, Schmidt M, Mills GB, Ang KK, Milas L, Fan Z. Targeting the phosphatidylinositol 3-kinase/Akt pathway for enhancing breast cancer cells to radiotherapy. Mol Cancer Ther. 2003;2(4):353-60.

70. Kavanagh BD, Dent P, Schmidt-Ullrich RK, Chen P, Mikkelsen RB. Calciumdependent stimulation of mitogen-activated protein kinase activity in A431 cells by low doses of ionizing radiation. Radiat Res. 1998;149(6):579-87.

71. Suy S, Anderson WB, Dent P, Chang E, Kasid U. Association of Grb2 with Sos and Ras with Raf-1 upon gamma irradiation of breast cancer cells. Oncogene. 1997;15(1):53-61.

72. Kavanagh BD, Lin P-S, Chen P, Schmidt-Ullrich RK. Radiation-induced enhanced proliferation of human squamous cancer cells in vitro: a release from inhibition by epidermal growth factor. Clin Cancer Res. 1995:1(12):1557-62.

73. Schmidt-Ullrich RK, Mikkelsen RB, Dent P, Todd DG, Valerie K, Kavanagh BD. Radiation-induced proliferation of the human A431 squamous carcinoma cells is dependent on EGFR tyrosine phosphorylation. Oncogene. 1997;15:1191-7.

74. Reardon DB, Contessa JN, Mikkelsen RB, Valerie K, Amir C, Dent P, SchmidtUllrich RK. Dominant negative EGFR-CD533 and inhibition of MAPK modify JNK1 activation and enhance radiation toxicity of human mammary carcinoma cells. Oncogene. 1999;18:4756-66.

\section{Ready to submit your research? Choose BMC and benefit from:}

- fast, convenient online submission

- thorough peer review by experienced researchers in your field

- rapid publication on acceptance

- support for research data, including large and complex data types

- gold Open Access which fosters wider collaboration and increased citations

- maximum visibility for your research: over $100 \mathrm{M}$ website views per year

At BMC, research is always in progress.

Learn more biomedcentral.com/submissions 